\title{
Article \\ Occupational Heat Stress: Multi-Country Observations and Interventions
}

\author{
Leonidas G. Ioannou ${ }^{1,2}{ }^{(D)}$, Konstantinos Mantzios ${ }^{1}$, Lydia Tsoutsoubi ${ }^{1}$ (D), Eleni Nintou ${ }^{1}$, Maria Vliora ${ }^{1}$, \\ Paraskevi Gkiata ${ }^{1}$, Constantinos N. Dallas ${ }^{1}$, Giorgos Gkikas ${ }^{1}$, Gerasimos Agaliotis ${ }^{1}$, Kostas Sfakianakis ${ }^{1}$, \\ Areti K. Kapnia ${ }^{1}$, Davide J. Testa ${ }^{1}$ D , Tânia Amorim ${ }^{1}$, Petros C. Dinas ${ }^{1}\left(\mathbb{D}\right.$, Tiago S. Mayor ${ }^{3}$, Chuansi Gao $^{4} \mathbb{D}^{\text {, }}$ \\ Lars Nybo ${ }^{2}$ and Andreas D. Flouris $1, * \mathbb{D}$
}

check for

updates

Citation: Ioannou, L.G.; Mantzios, K.; Tsoutsoubi, L.; Nintou, E.; Vliora,

M.; Gkiata, P.; Dallas, C.N.; Gkikas,

G.; Agaliotis, G.; Sfakianakis, K.; et al.

Occupational Heat Stress:

Multi-Country Observations and Interventions. Int. J. Environ. Res. Public Health 2021, 18, 6303. https:// doi.org/10.3390/ijerph18126303

Academic Editor: June T. Spector

Received: 11 April 2021

Accepted: 7 June 2021

Published: 10 June 2021

Publisher's Note: MDPI stays neutral with regard to jurisdictional claims in published maps and institutional affiliations.

Copyright: (c) 2021 by the authors. Licensee MDPI, Basel, Switzerland This article is an open access article distributed under the terms and conditions of the Creative Commons Attribution (CC BY) license (https:// creativecommons.org/licenses/by/ $4.0 /)$.
1 FAME Laboratory, Department of Physical Education and Sport Science, University of Thessaly, 42100 Trikala, Greece; ioannouLG@gmail.com (L.G.I.); konstantinosmantzios@gmail.com (K.M.); lydiatsoutsoubi@gmail.com (L.T.); enintou@gmail.com (E.N.); mvliora@gmail.com (M.V.); gkiata.vivi@gmail.com (P.G.); constantinedallas@gmail.com (C.N.D.); ggkikas@uth.gr (G.G.); gagaliotis@uth.gr (G.A.); ksfakianakis98@gmail.com (K.S.); Areti.kapnia@gmail.com (A.K.K.); davide.testa13@gmail.com (D.J.T.); tania.patricia.amorim@gmail.com (T.A.); petros.cd@gmail.com (P.C.D.)

2 Department of Nutrition, Exercise and Sports, August Krogh Building, University of Copenhagen, 2100 Copenhagen, Denmark; nybo@nexs.ku.dk

3 SIMTECH Laboratory, Transport Phenomena Research Centre, Engineering Faculty of Porto University, 4200-465 Porto, Portugal; tiago.sottomayor@fe.up.pt

4 Thermal Environment Laboratory, Division of Ergonomics and Aerosol Technology, Department of Design Sciences, Faculty of Engineering, Lund University, 22100 Lund, Sweden; chuansi.gao@design.lth.se

* Correspondence: andreasflouris@gmail.com; Tel.: +30-2431-047-042

Abstract: Background: Occupational heat exposure can provoke health problems that increase the risk of certain diseases and affect workers' ability to maintain healthy and productive lives. This study investigates the effects of occupational heat stress on workers' physiological strain and labor productivity, as well as examining multiple interventions to mitigate the problem. Methods: We monitored 518 full work-shifts obtained from 238 experienced and acclimatized individuals who work in key industrial sectors located in Cyprus, Greece, Qatar, and Spain. Continuous core body temperature, mean skin temperature, heart rate, and labor productivity were collected from the beginning to the end of all work-shifts. Results: In workplaces where self-pacing is not feasible or very limited, we found that occupational heat stress is associated with the heat strain experienced by workers. Strategies focusing on hydration, work-rest cycles, and ventilated clothing were able to mitigate the physiological heat strain experienced by workers. Increasing mechanization enhanced labor productivity without increasing workers' physiological strain. Conclusions: Empowering laborers to self-pace is the basis of heat mitigation, while tailored strategies focusing on hydration, work-rest cycles, ventilated garments, and mechanization can further reduce the physiological heat strain experienced by workers under certain conditions.

Keywords: heat stress; work; mitigation; labor productivity; physiological strain; hydration; breaks; ventilated garments; mechanization; ice slurry

\section{Introduction}

Occupational heat stress (OH-stress) increases the physiological heat strain experienced by workers (OH-strain) leading to a higher risk of diseases and health problems including dehydration [1], occupational accidents [2-4], absenteeism [5], as well as chronic kidney injuries [6]. Moreover, $\mathrm{OH}$-strain leads to reduced capacity for work and lower productivity output [6-8]. By the end of the century, five out of ten people will be exposed to harmful climatic conditions under a mild climate change scenario (assuming drastic reduction of greenhouse gases) and more than seven out of ten people under a scenario of 
growing gas emissions [9]. This, of course, will be more pronounced for workers in agriculture and construction [10], due to the requirement to perform manual labor outdoors and the lack of cost-effective heat mitigation strategies for these occupational settings. Beyond these obvious cases of occupational heat exposure, climate-dependent industrial sectors such as tourism are likely to experience a lengthening of their summer seasons [11], leading their workers to experience a more prolonged working season in the heat.

Working in climate-vulnerable industries (e.g., agriculture, construction, and tourism) often translates to prolonged manual labor in hot environments. While it would be wrong to assume that all workers in these industries are exposed to $\mathrm{OH}$-stress, this issue certainly involves a very large number of workers since these sectors currently employ about half of the world's labor force: agriculture employs $~ 32 \%$ [12]; construction employs $\sim 10 \%$ [13]; and tourism employs $\sim 8 \%$ [14] of all workers. The monetary turnover associated with these sectors plays a primary role in the global economy, while the projected heat-induced labor loss in monetary terms is expected to be as high as 2216 billion EUR ( 2400 billion USD) by $2030[10,15]$.

Protecting workers' health while maintaining labor productivity is vital [16-18] and has driven many researchers to investigate the effectiveness of different heat mitigation strategies [19,20]. Specifically, heat mitigation strategies such as planned breaks [21], use of personal cooling vests [22,23], ice slurry consumption [22,24], optimized clothing [25], and ventilated garments $[26,27]$ were previously tested in lab settings for mitigating the $\mathrm{OH}$ strain experienced by individuals performing physical work (typically exercise). However, there is limited knowledge regarding the capacity of these heat mitigation strategies to protect workers' health and labor productivity in occupational settings, taking into account real-life work-related parameters. For example, job task requirements and complexities, self-pacing, and sun exposure are only some of the parameters that are difficult to consider in laboratory settings and are known to affect the physiological heat strain experienced by someone $[7,28]$. To address this knowledge gap, a series of observational and interventional field studies were conducted in different countries around the globe. The first aim of the current study was to investigate the effects of OH-stress on the thermo-physiological responses and labor productivity of workers in agriculture, construction, and tourism sectors in different countries. The second aim of the study was to examine different costeffective heat mitigation strategies to reduce the $\mathrm{OH}$-strain experienced by workers in the aforementioned industrial sectors, without jeopardizing their capacity to perform labor.

\section{Materials and Methods}

The experimental protocol (ClinicalTrials.gov ID: NCT04160728) for these field experiments was approved by the Bioethical Committee of Department of Physical Education and Sport Science of the University of Thessaly and the National Bioethical Review Board of Cyprus in accordance with the Declaration of Helsinki. This series of field experiments involved monitoring typical acclimatized adult workers who live in the area and perform similar work tasks on a daily basis. No exclusion criteria, other than not being an adult, experienced, and acclimatized worker, were applied. Therefore, workers with different sex, age, body mass, body stature, ethnicity, education, and socio-economic background were recruited in the present study.

\subsection{Observational Studies}

To examine the effects of $\mathrm{OH}$-stress on the thermo-physiological responses and labor productivity of workers in agriculture, construction, and tourism sectors, we collected physiological (core temperature, mean skin temperature, and heart rate) and labor (work intensity) data from 99 workers during full work-shifts in agriculture (Greece), construction (Spain), and tourism (Greece) industries. Prior to their participation in the study, written informed consent was obtained from all volunteers after a detailed explanation of all the procedures involved. It is important to note that in our measures in the agriculture sector of Greece, there were incorporated workers (Romani ethnic group) who did not consent to 
measurements of core temperature, mean skin temperature, and heart rate as well as to assessing their personal characteristics (body mass, body stature, and age). Nevertheless, they agreed to participate in the study and have their labor data (see below "time-motion analysis") collected.

Self-reported age, body stature, and body mass were collected prior to the study. Continuous core temperature $\left(\mathrm{T}_{\text {core }}\right)$ and mean skin temperature $\left(\mathrm{T}_{\text {sk }}\right)$ data were collected using telemetric capsules (BodyCap, Caen, France), and wireless thermistors (iButtons type DS1921H, Maxim/Dallas Semiconductor Corp., USA), respectively. Skin temperature data were collected from four body sites (chest, arm, thigh, and leg) and were expressed as $\mathrm{T}_{\mathrm{sk}}$ using the formula of Ramanathan $\left(\mathrm{T}_{\mathrm{sk}}=0.3\right.$ (chest + arm $)+0.2$ (thigh + leg) $)$ [29] . Furthermore, continuous environmental data (air temperature $\left({ }^{\circ} \mathrm{C}\right)$, globe temperature $\left({ }^{\circ} \mathrm{C}\right)$, relative humidity $(\%)$, and air velocity $(\mathrm{m} / \mathrm{s})$ ) were collected using portable weather stations (Kestrel 5400FW, Nielsen-Kellerman, Pennsylvania, USA) installed in close proximity to the workers. The same weather station provides measures of Wet-Bulb Globe Temperature (WBGT) with an accuracy of $\pm 0.7^{\circ} \mathrm{C}$ in ambient temperatures ranging between -29 and $70{ }^{\circ} \mathrm{C}$ according to the developer's manual. An established method of second-by-second time motion analysis was utilized to examine the labor effort of agriculture workers [7,30], while real-time task analysis was utilized to evaluate the labor intensity of workers in tourism and construction sectors. Real-time task analysis is based on the premise of the aforementioned time-motion analysis. The only difference between the two methods is that real-time task analysis is performed live at the work site, while time-motion analysis is based on video recordings taken at the work site and analyzed at a later time. It is important to note that the data collection took place across multiple days characterized by different ambient conditions. All the data collected throughout the experiments are presented in Figure 1.

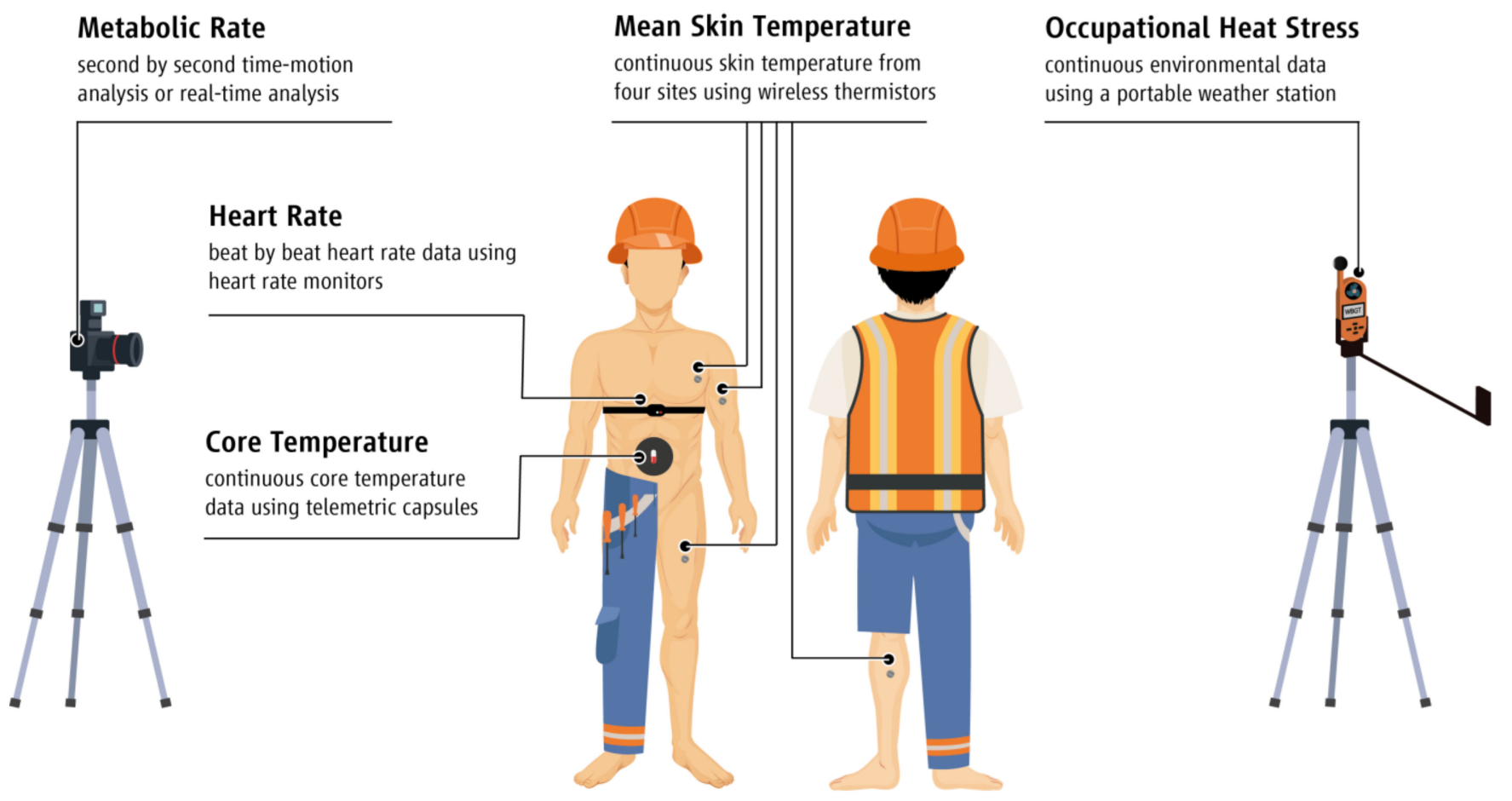

Figure 1. Data collection throughout the experiments.

Time-motion analysis was conducted for 11 different activities. Previous knowledge related to the energy cost of different activities [31,32] was used to determine the intensity characterizing each work task (Table A1). Real-time task analysis was conducted using different levels of work intensity (i.e., rest, low/medium/high intensity) based on the International Standard 8996 on the determination of metabolic rate. Specifically, rest 
$\left(65 \mathrm{~W} / \mathrm{m}^{2}\right)$ was characterized as any activity involving resting and/or sitting at ease. Low-intensity labor $\left(100 \mathrm{~W} / \mathrm{m}^{2}\right)$ included activities incorporating "hand and arm work" or "hand and leg work", such as driving vehicles in normal conditions, machining, and casual walking (at a speed up to $2.5 \mathrm{~km} / \mathrm{h}$ ). Moderate-intensity labor $\left(165 \mathrm{~W} / \mathrm{m}^{2}\right)$ included activities involving "hand and arm work", "arm and leg work", or "arm and trunk work" such as working with construction equipment, weeding, picking fruits, or walking (at a speed of $2.5-5.5 \mathrm{~km} / \mathrm{h})$. High-intensity labor $\left(230 \mathrm{~W} / \mathrm{m}^{2}\right)$ included any activity involving using intense arm and trunk work, carrying heavy material, pushing or pulling heavily, or walking (at a speed of $5.5-7.0 \mathrm{~km} / \mathrm{h}$ ).

\subsection{Interventional Studies}

To examine the capacity of different heat mitigation strategies to reduce the $\mathrm{OH}$-strain experienced by workers across various industrial sectors, we compared a "business as usual" (BAU) scenario, where workers followed their normal work routine, against different heat mitigation strategies in each industrial sector across different countries (Cyprus, Greece, Qatar, and Spain). The BAU and heat mitigation strategies were randomly allocated among four full work-shifts and were tested after consulting with the management of each worksite, aiming to test economically viable and feasible interventions without jeopardizing workers' normal workflow. All the tested strategies incorporated the same data collection (Figure 1) and procedures as during the observational field experiments. In addition, continuous heart rate (HR) was collected using wireless heart rate monitors (Polar Team2, Polar Electro Oy, Kempele, Finland), as well as urine samples collected at the start and the end of the BAU and hydration scenarios to evaluate the hydration status of each worker. Urine-specific gravity was assessed for each urine sample using a refractometer (PAL-10S, ATAGO CO., LTD., Fukaya, Saitama Prefecture, Japan) and was classified as either hydrated $(<1.020)$ or dehydrated $(\geq 1.020)$ [33].

\subsubsection{Agriculture Industry}

In agriculture, we tested three different strategies in Cyprus (06:00-14:00 work-shift) and three more strategies in Qatar (04:30-11:00 work-shift). In Cyprus, agriculture workers were provided with (1) "planned breaks" (i.e., $90 \mathrm{~s}$ of break every half hour of work) and (2) a "mechanical fruit cart" (i.e., machinery which carries up to $225 \mathrm{~kg}$ of crops with minimal labor effort) aiming to reduce workers' metabolic heat production, as well as with (3) "ventilated garments" (i.e., short-sleeved shirts with integrated electric fans) aiming to increase their evaporative and convective heat losses. In Qatar, agriculture workers were (1) advised (but not forced) to drink $750 \mathrm{~mL}$ of water every hour (supplemented with a total of one tablespoon of salt, for the entire work-shift, to avoid hyponatremia) from the start until the end of the work-shift, (2) provided with "evaporative garments" (i.e., breathable lightweight work shirt and trousers that allowed the wearer to wet the collar, cuffs, and pocket pouches with water), and (3) provided with ten minutes of a planned break (workers were advised to rest and hydrate in the shade) every 50 min of continuous work from 06:00 to 11:00. Salt supplementation during the hydration strategy was considered only for workers who had not been diagnosed with high blood pressure and/or other cardiovascular abnormalities. Moreover, the suggested amount of salt ( $15 \mathrm{~g})$ was calculated based on our predictions which indicate that a typical worker is expected to secrete $\sim 6 \mathrm{~L}$ of sweat during an 8-h shift in the heat [30] and the known concentration of salt in sweat (2.1 to $3.2 \mathrm{~g} / \mathrm{L}$ ) [34]. One day prior to the evaporative garments strategy in Qatar, workers were provided with a demonstration explaining in detail the different properties of the evaporative garments as well as how they should be used. Thereafter, the workers were free to use the evaporative garments as desired in order to assess how they would be eventually used in real-life conditions. 


\subsubsection{Construction Industry}

In construction, we tested three different heat mitigation strategies in Qatar (three different scenarios for each one of the following work-shifts: (a) 00:00-11:00, (b) 15:30-02:30, and (c) 06:00-17:00) and three more strategies in Spain (09:00-19:00 work-shift). In Qatar, we tested the (1) hydration, (2) evaporative garments, and (3) work-rest cycle strategies as described above for the agriculture workers in the same country. However, during the BAU scenario of the construction workers studied in Qatar, a raft of other heat mitigation strategies were already in place at the work site including (1) shaded areas every 100-200 m, (2) water stations every $300-400 \mathrm{~m}$, (3) an obligation for each worker to carry a $1 \mathrm{~L}$ water bottle throughout the work-shift, (4) air-conditioned rest areas to be used during planned breaks, and (5) education on the effects of $\mathrm{OH}$-stress and dehydration by a large team of safety and welfare officers, with reminders using large signs throughout the site in languages understood by workers.

In Spain, we provided construction workers with (1) $750 \mathrm{~mL}$ of cold water (but they were not forced to drink) every hour (supplemented with a total of one tablespoon of salt, for the entire work-shift, to avoid hyponatremia), (2) two breaks of seven minutes (at 12:30 and 16:30) in the "planned break" scenario, and (3) $300 \mathrm{~mL}$ of crushed ice (ice slurry) every hour. During the hydration strategy, salt supplementation was considered only for workers who had not been diagnosed with high blood pressure and / or other cardiovascular abnormalities. Moreover, the suggested amount of salt $(\sim 15 \mathrm{~g})$ was calculated based on our predictions which indicate that a typical worker is expected to secrete $\sim 6 \mathrm{~L}$ of sweat during an 8-h shift in the heat [30] and the known concentration of salt in sweat (2.1 to $3.2 \mathrm{~g} / \mathrm{L}$ ) [34]. Furthermore, during the BAU scenario of the construction workers examined in Spain, a raft of other heat mitigation strategies was already in place at the work site including (1) shaded areas every 50-100 m, (2) water stations every 50-100 m, and (3) air-conditioned rest areas to be used during planned breaks.

\subsubsection{Tourism Industry}

Three different heat mitigation strategies were tested in the tourism industry of Greece. Specifically, tourism workers were provided with (1) $90 \mathrm{~s}$ of a planned break every $30 \mathrm{~min}$ of continuous work, (2) ice slurries ( $3.5 \mathrm{~mL}$ per body mass kilogram) every hour of continuous work, and (3) two minutes of a planned break combined with ice slurry consumption $(2.4 \mathrm{~g}$ per body mass kilogram) every hour of continuous work.

\subsection{Data Analysis}

In observational studies, the collected WBGT data were rounded to the closest integer. Thereafter, we calculated the average $\mathrm{T}_{\text {core }}, \mathrm{T}_{\mathrm{sk}}$, and metabolic rate of workers during exposure in each degree WBGT. Pearson's correlation coefficient was used to examine the relationships between the average $\mathrm{T}_{\text {core, }}, \mathrm{T}_{\mathrm{sk}}$, and metabolic rate in each degree WBGT and the thermal stress (i.e., rounded WBGT values) experienced by workers. The magnitude of the observed relationships was determined based on previous literature [35]. Linear and non-linear regression analyses with prediction intervals were used to examine if thermal stress (rounded WBGT values) can predict the $\mathrm{OH}$-strain (i.e., average $\mathrm{T}_{\text {core }}$ and $\mathrm{T}_{\text {sk }}$ at each degree WBGT) and labor effort (average metabolic rate at each degree WBGT) experienced by workers in each industrial sector.

To compare the different heat mitigation strategies conducted in each industrial sector against the BAU scenario, workers should be exposed to environments characterized by the same heat stress. Although all heat mitigation strategies were scheduled based on weather forecasts to imply the same thermal stress as during the BAU, in three out of the fifteen scenarios, we identified a significant difference $\left(\geq 1^{\circ} \mathrm{C}\right.$ WBGT $)$ in the thermal stress between the BAU scenario and the heat mitigation strategies. In such cases, the Predicted Heat Strain model [30] was utilized to homogenize the data by computing the expected difference in $\mathrm{T}_{\text {core, }} \mathrm{T}_{\mathrm{sk}}$, and HR (33 bpm (average thermal cardiac reactivity) per degree of difference in $\mathrm{T}_{\text {core }}$ ) between the conflicted scenarios, and thereafter subtracting/adding them from/to 
the actual values collected in the field. For instance, in a hypothetical case where an agriculture worker (height $=180 \mathrm{~cm}$ and weight $=75 \mathrm{~kg}$ ) was exposed to an environment of $29^{\circ} \mathrm{C}$ WBGT (air temperature $=35^{\circ} \mathrm{C}$; globe temperature $=39.8^{\circ} \mathrm{C}$; relative humidity $=40 \%$; and wind speed $=0.5 \mathrm{~m} / \mathrm{s}$ ) during the BAU scenario, compared to an environment of $30{ }^{\circ} \mathrm{C}$ WBGT (air temperature $=35.9{ }^{\circ} \mathrm{C}$; globe temperature $=41.0^{\circ} \mathrm{C}$; relative humidity $=41 \%$; and wind speed $=0.6 \mathrm{~m} / \mathrm{s}$ ) during the hydration strategy, we computed the expected mean differences in $\mathrm{T}_{\text {core, }} \mathrm{T}_{\mathrm{sk}}$, and $\mathrm{HR}$, and we subtracted them from the actual mean values during the hydration scenario. In this case, $0.12{ }^{\circ} \mathrm{C}, 0.19{ }^{\circ} \mathrm{C}$, and $4.11 \mathrm{bpm}$ were subtracted from the actual collected $\mathrm{T}_{\text {core }}, \mathrm{T}_{\mathrm{sk}}$, and HR, respectively. Thereafter, paired t-tests alongside Cohen's d effect sizes were used to examine possible differences between the BAU scenario and all the tested heat mitigation strategies. The magnitude of effect sizes [36] was determined as follows: $d(0.01)=$ very small; $d(0.2)=$ small; $d(0.5)=$ medium; $\mathrm{d}(0.8)=$ large; $\mathrm{d}(1.2)$ = very large; and $\mathrm{d}(2.0)=$ huge. Relative risks were calculated to investigate the odds of being dehydrated (i.e., prevalence of dehydration) during the BAU and hydration scenarios. The relative risks, their standard error, and 95\% confidence intervals were calculated based on previous methodology [37].

Statistical analyses were conducted using the SPSS v25.0 (IBM, Armonk, NY, USA), the OriginPro 2020 (OriginLab Northhampton, MA, USA) and the Excel spreadsheets (Microsoft Office, Microsoft, Washington, USA). The level of significance for these analyses was set at $p<0.05$.

\section{Results}

The study involved monitoring 518 full work-shifts obtained from 238 experienced and acclimatized (living in the area for more than two months) workers. Detailed information on participants' anthropometric characteristics is presented in Table 1.

Table 1. Workers' personal characteristics (mean \pm SD). Asterisk indicates that no anthropometric data were collected from all participants.

\begin{tabular}{|c|c|c|c|c|}
\hline \multicolumn{5}{|c|}{ Observational Studies } \\
\hline Sector & Workers $(n)$ & Weight $(\mathrm{kg})$ & Height $(\mathrm{cm})$ & Age (Years) \\
\hline Agriculture (Greece) & $36(7) *$ & $75.4 \pm 13.2$ & $169.1 \pm 4.9$ & $39.9 \pm 14.2$ \\
\hline Construction (Spain) & 14 & $79.6 \pm 11.1$ & $174.3 \pm 8.9$ & $43.3 \pm 10.2$ \\
\hline Tourism (Greece) & 49 & $75.6 \pm 14.7$ & $1.7 \pm 0.1$ & $34.5 \pm 9.5$ \\
\hline \multicolumn{5}{|c|}{ Interventional Studies } \\
\hline & Workers $(n)$ & Weight (kg) & Height $(\mathrm{cm})$ & Age (years) \\
\hline \multicolumn{5}{|c|}{ Agriculture (Cyprus) $n=6$} \\
\hline Work/rest ratio & 6 & $77.0 \pm 16.2$ & $168.3 \pm 8.5$ & $39.2 \pm 11.8$ \\
\hline Fruit cart (eCart) & 6 & $77.0 \pm 16.2$ & $168.3 \pm 8.5$ & $39.2 \pm 11.8$ \\
\hline Ventilated garments & 6 & $77.0 \pm 16.2$ & $168.3 \pm 8.5$ & $39.2 \pm 11.8$ \\
\hline \multicolumn{5}{|c|}{ Agriculture (Qatar) $n=34$} \\
\hline Work/rest ratio & 24 & $66.4 \pm 10.0$ & $170.6 \pm 5.7$ & $31.5 \pm 7.5$ \\
\hline Hydration & 26 & $65.2 \pm 9.4$ & $169.7 \pm 5.8$ & $32.1 \pm 7.2$ \\
\hline Evaporative garments & 12 & $67.3 \pm 9.2$ & $170.1 \pm 4.3$ & $35.3 \pm 8.5$ \\
\hline \multicolumn{5}{|c|}{ Construction (Qatar) $n=83$} \\
\hline Work/rest ratio & 69 & $65.3 \pm 8.4$ & $164.9 \pm 5.7$ & $34.4 \pm 8.3$ \\
\hline Hydration & 53 & $65.7 \pm 8.1$ & $165.2 \pm 5.8$ & $34.3 \pm 9.2$ \\
\hline Evaporative garments & 32 & $65.1 \pm 8.1$ & $164.5 \pm 5.9$ & $35.9 \pm 7.8$ \\
\hline \multicolumn{5}{|c|}{ Construction (Spain) $n=10$} \\
\hline Work/rest ratio & 10 & $85.9 \pm 14.4$ & $175.8 \pm 10.9$ & $41.5 \pm 7.3$ \\
\hline Hydration & 9 & $77.9 \pm 15.0$ & $158.2 \pm 11.5$ & $39.0 \pm 5.0$ \\
\hline Ice slurry & 9 & $77.9 \pm 15.0$ & $158.2 \pm 11.5$ & $39.0 \pm 5.0$ \\
\hline \multicolumn{5}{|c|}{ Tourism (Greece) $n=6$} \\
\hline Work/rest ratio & 6 & $71.2 \pm 9.8$ & $171.2 \pm 7.4$ & $30.5 \pm 8.3$ \\
\hline Ice slurry & 6 & $71.2 \pm 9.8$ & $171.2 \pm 7.4$ & $30.5 \pm 8.3$ \\
\hline Combined & 6 & $71.2 \pm 9.8$ & $171.2 \pm 7.4$ & $30.5 \pm 8.3$ \\
\hline
\end{tabular}




\subsection{Observational Studies}

To investigate the effects of $\mathrm{OH}$-stress on the thermophysiological responses and labor effort of workers in agriculture, construction, and tourism sectors, 99 workers from Cyprus, Greece, and Spain were monitored during their full work-shift. The environmental conditions during the observations in agriculture (air temperature: $23.1 \pm 6.4^{\circ} \mathrm{C}$; globe temperature: $35.0 \pm 6.6^{\circ} \mathrm{C}$; relative humidity: $50.4 \pm 8.8 \%$; and air velocity: $1.2 \pm 0.8 \mathrm{~m} / \mathrm{s}$ ) ranged from 14.5 to $30.3^{\circ} \mathrm{C}$ WBGT. The environmental conditions during the observations in construction (air temperature: $26.6 \pm 3.9^{\circ} \mathrm{C}$; globe temperature: $32.1 \pm 8.3^{\circ} \mathrm{C}$; relative humidity: $49.8 \pm 13.3 \%$; and air velocity: $0.4 \pm 0.8 \mathrm{~m} / \mathrm{s}$ ) ranged from 19.2 to $29.2{ }^{\circ} \mathrm{C}$ WBGT. The environmental conditions during the observations in the tourism industry (air temperature: $29.8 \pm 2.6{ }^{\circ} \mathrm{C}$; globe temperature: $31.1 \pm 3.7^{\circ} \mathrm{C}$; relative humidity: $54.3 \pm 8.5 \%$; and air velocity: $0.2 \pm 0.4 \mathrm{~m} / \mathrm{s}$ ) ranged from 20.2 to $32.4^{\circ} \mathrm{C}$ WBGT.

Strong relationships were identified between WBGT and the $T_{\text {sk }}$ of people who worked in agriculture $(\mathrm{r}=0.970, p<0.001)$, construction $(\mathrm{r}=0.922, p<0.001)$, and tourism $(\mathrm{r}=0.595$, $p=0.032$ ) sectors (Figure 2). Similarly, linear regressions demonstrated that there is a $0.31{ }^{\circ} \mathrm{C}$, $0.23{ }^{\circ} \mathrm{C}$, and $0.09^{\circ} \mathrm{C}$ increase in $\mathrm{T}_{\text {sk }}$ for every $1{ }^{\circ} \mathrm{C}$ increase in WBGT for people who work in agriculture $\left(\mathrm{R}^{2}=0.941 ; \mathrm{F}_{(1,10)}=159.098, p<0.001\right)$, construction $\left(\mathrm{R}^{2}=0.850 ; \mathrm{F}_{(1,8)}=45.443\right.$, $p<0.001)$, and tourism $\left(\mathrm{R}^{2}=0.354 ; \mathrm{F}_{(1,11)}=6.029, p=0.032\right)$ sectors, respectively (Figure 2 and Table A2).

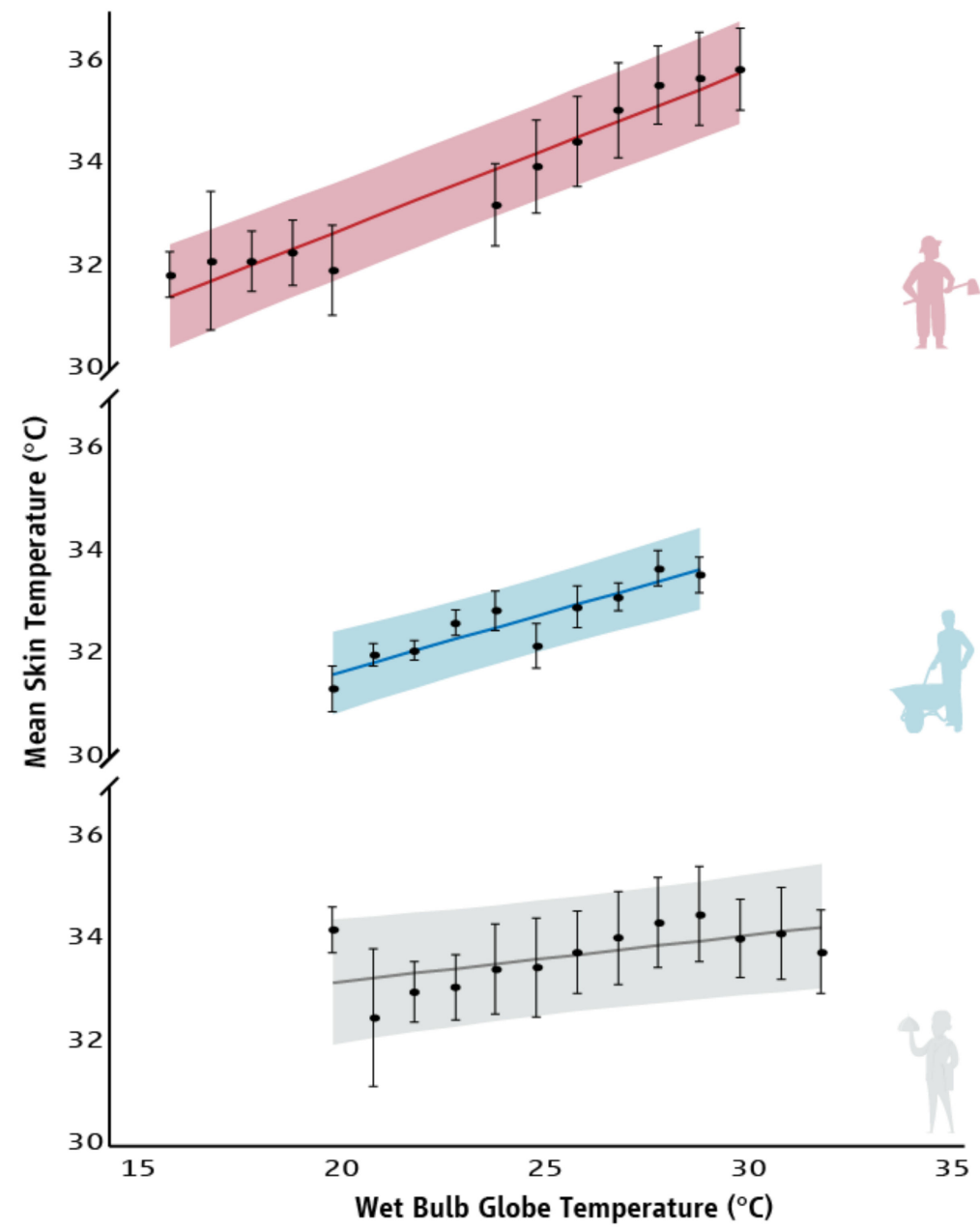

Figure 2. Relationship between Wet-Bulb Globe Temperature and the mean skin temperature (average $\pm \mathrm{SD}$ ) of people who work in agriculture (red), construction (blue), and tourism (grey) sectors. Lines represent the slope of the predicted relationship between Wet-Bulb Globe Temperature and the mean skin temperature of workers. Shadings correspond to the $95 \%$ prediction intervals of the means. 
No relationship was identified between WBGT and the $\mathrm{T}_{\text {core }}$ of agriculture workers $(\mathrm{r}=-0.052, p=0.872)$. On the other hand, strong relationships were identified between WBGT and the $\mathrm{T}_{\text {core }}$ of people who work in construction $(\mathrm{r}=0.765, p=0.010)$ and tourism $(r=0.646, p=0.017)$ sectors (Figure 3$)$. Furthermore, linear regressions showed no effect of $\mathrm{OH}$-stress on the $\mathrm{T}_{\text {core }}$ of agriculture workers, while there is a $0.05{ }^{\circ} \mathrm{C}$ increase in $\mathrm{T}_{\text {core }}$ for every $1{ }^{\circ} \mathrm{C}$ increase in WBGT for people who work in construction $\left(\mathrm{R}^{2}=0.585\right.$; $\mathrm{F}_{(1,8)}=11.254, p=0.010$; Table A2). A biphasic regression $\left(\mathrm{R}^{2}=0.852 ; \mathrm{F}_{(2,10)}=28.678\right.$, $p<0.001)$ demonstrated that there is an increase of $\sim 0.4{ }^{\circ} \mathrm{C}$ in the $\mathrm{T}_{\text {core }}$ of tourism workers for every $1{ }^{\circ} \mathrm{C}$ increase in WBGT above $30^{\circ} \mathrm{C}$ (Figure 3 and Table A2).

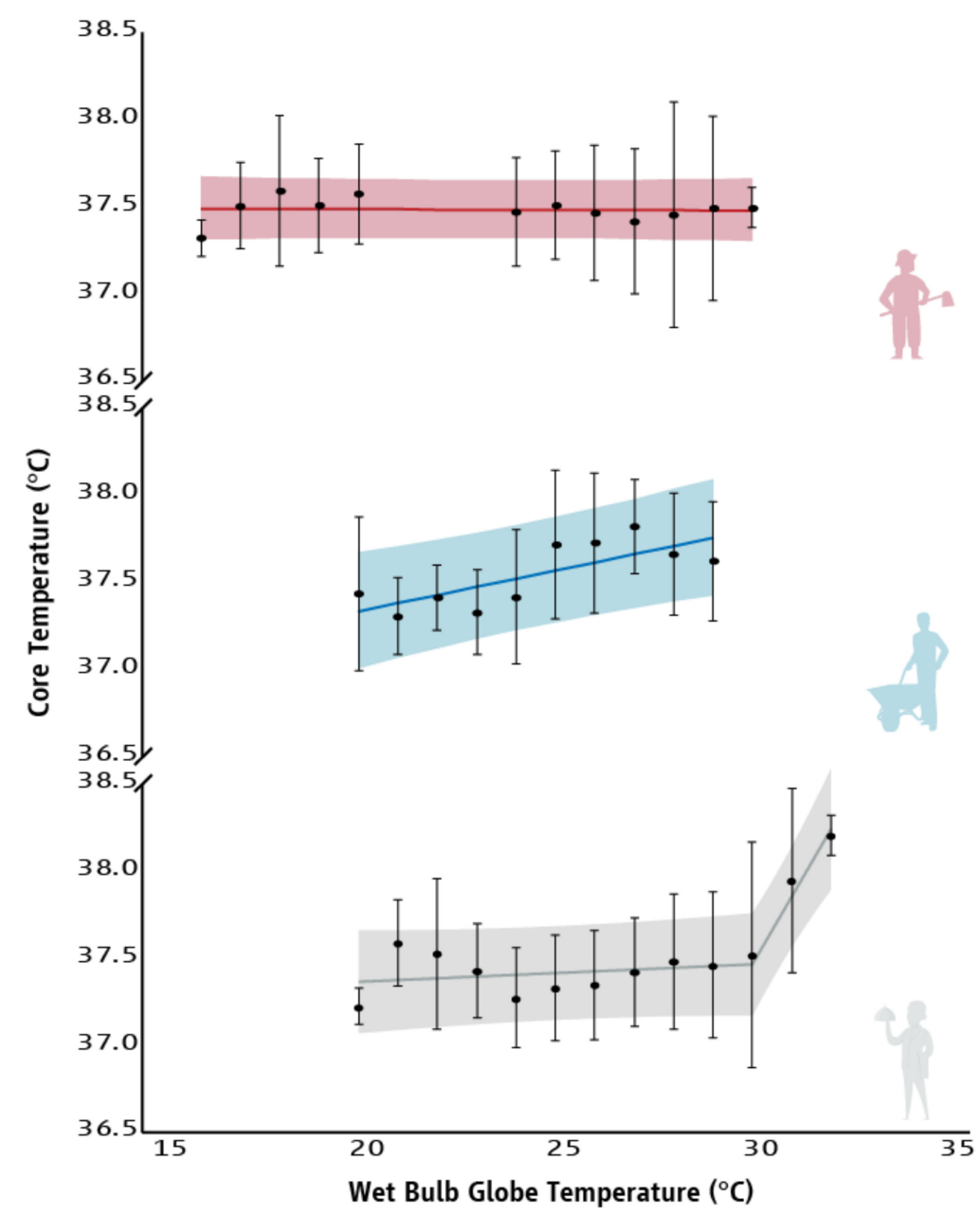

Figure 3. Relationship between Wet-Bulb Globe Temperature and the core temperature (average $\pm \mathrm{SD}$ ) of people who work in agriculture (red), construction (blue), and tourism (grey) sectors. Lines represent the slope of the predicted relationship between Wet-Bulb Globe Temperature and the core temperature of workers. Shadings correspond to the $95 \%$ prediction intervals of the means.

A very strong relationship between WBGT and the metabolic rate of agriculture workers $(r=-0.787, p<0.001)$ was found (Figure 4). On the other hand, no statistically significant relationships were found between WBGT and the metabolic rate of construction $(r=-0.249, p=0.487)$ or tourism $(r=0.035, p=0.908)$ workers (Figure 4$)$. Linear regressions demonstrated that there is a $3.1 \mathrm{~W} / \mathrm{m}^{2}$ decrease in the metabolic rate of agriculture workers $\left(\mathrm{R}^{2}=0.619 ; \mathrm{F}_{(1,14)}=22.719, p<0.001\right)$ for every $1^{\circ} \mathrm{C}$ increase in WBGT, but no statistically significant relationships in construction $(p=0.487)$ or tourism $(p=0.908)$ sectors (Figure 4 and Table A2). 


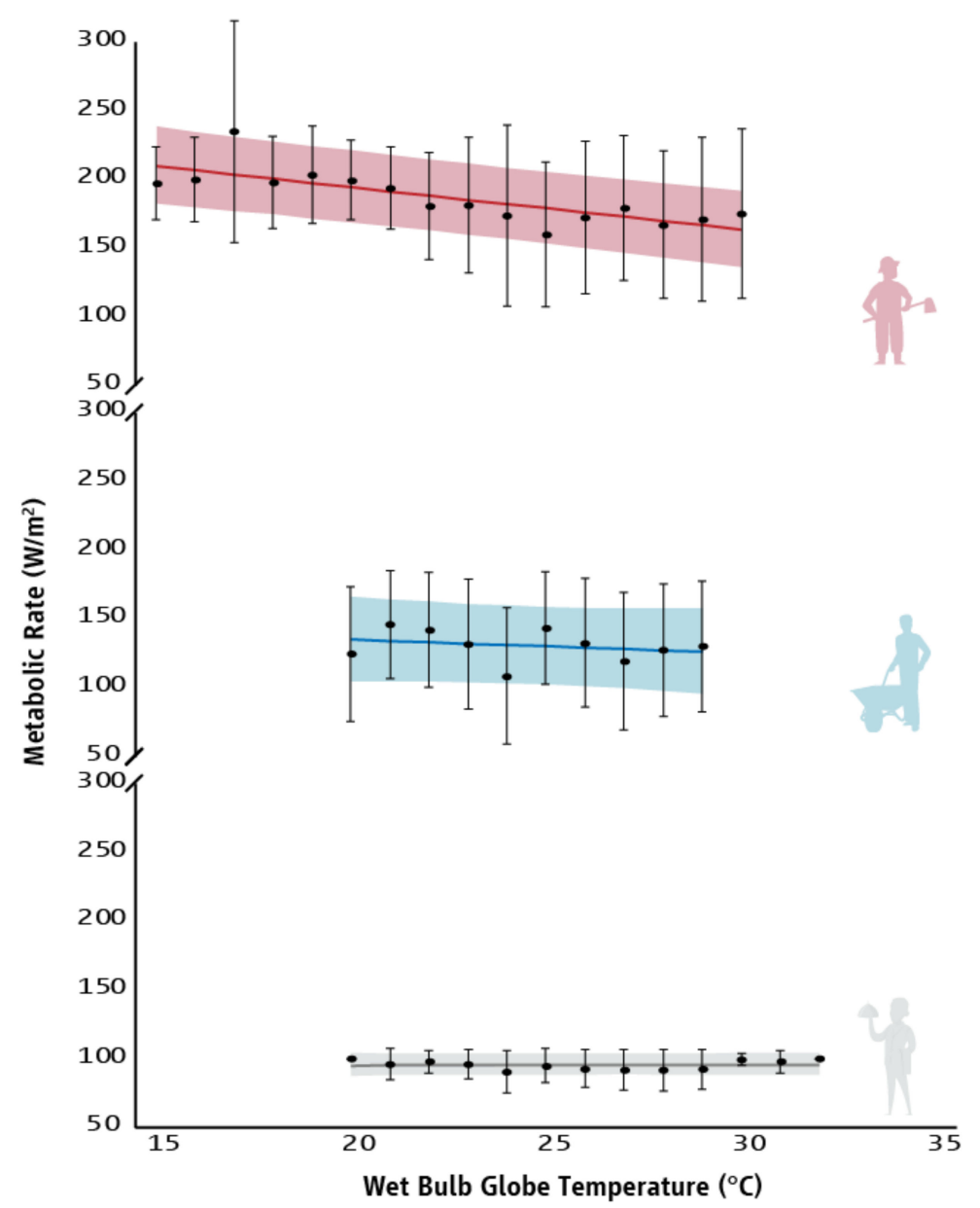

Figure 4. Relationship between Wet-Bulb Globe Temperature and the metabolic rate/work intensity (average $\pm \mathrm{SD}$ ) of people who work in agriculture (red), construction (blue), and tourism (grey) sectors. Lines represent the slope of the predicted relationship between Wet-Bulb Globe Temperature and the metabolic rate/work intensity of workers. Shadings correspond to the $95 \%$ prediction intervals of the means.

\subsection{Interventional Studies}

To examine possible cost-effective heat mitigation strategies to reduce the $\mathrm{OH}$-strain, 139 workers were monitored in agriculture, construction, and tourism industries over four full work-shifts characterized by similar thermal stress (Table A3). Overall, ten different heat mitigation strategies (five of which were investigated in different industries) were tested to examine their capacity to mitigate the $\mathrm{OH}$-strain experienced by people who work under heat stress. Detailed information regarding the efficacy of each heat mitigation strategy is presented below.

\subsubsection{Agriculture Industry}

In Cyprus, the use of the "mechanical fruit cart" did not significantly lower the $\mathrm{T}_{\text {core }}$ $(p=0.364), \mathrm{T}_{\mathrm{sk}}(p=0.890), \mathrm{HR}(p=0.216)$, or labor effort $(p=0.308)$ of agriculture workers (Figure 5). However, workers picked 63\% more crop when using the "mechanical fruit cart" $(4400 \mathrm{~kg})$ compared to the BAU scenario $(2700 \mathrm{~kg})$. Providing agriculture workers with "planned breaks" did not significantly alter their $\mathrm{T}_{\text {core }}(p=0.492), \mathrm{T}_{\mathrm{sk}}(p=0.893), \mathrm{HR}$ $(p=0.079)$, or labor effort $(p=0.357)$ (Figure 5). On the other hand, we identified that "ventilated garments" were able to reduce the $\mathrm{T}_{\mathrm{sk}}(p=0.009 ; \mathrm{d}=-1.59)$ of agriculture workers without impacting their $\mathrm{T}_{\text {core }}(p=0.124), \mathrm{HR}(p=0.918)$, or labor effort $(p=0.483)$ (Figure 5) during the work-shift. 

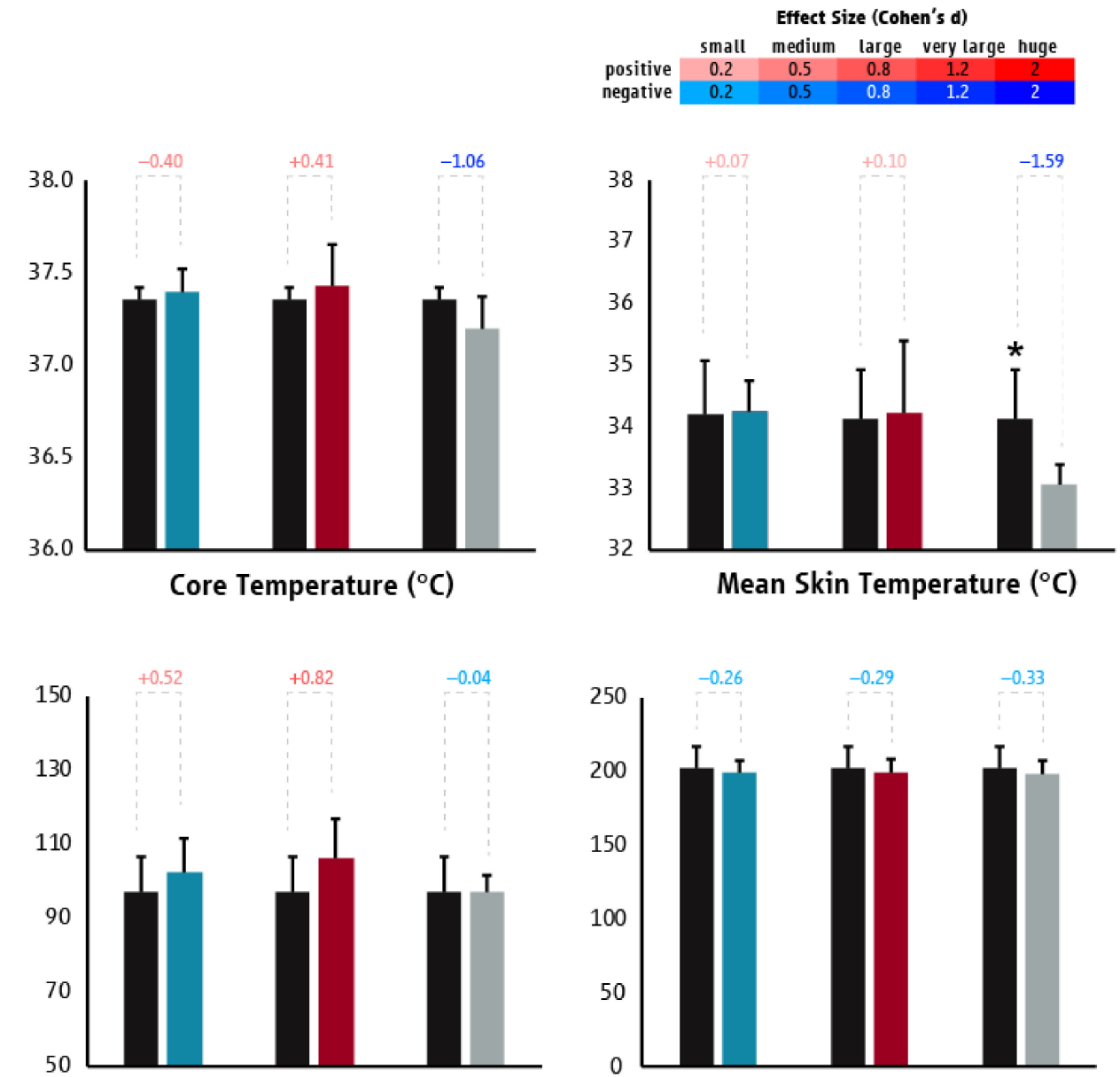

Heart Rate (bpm)
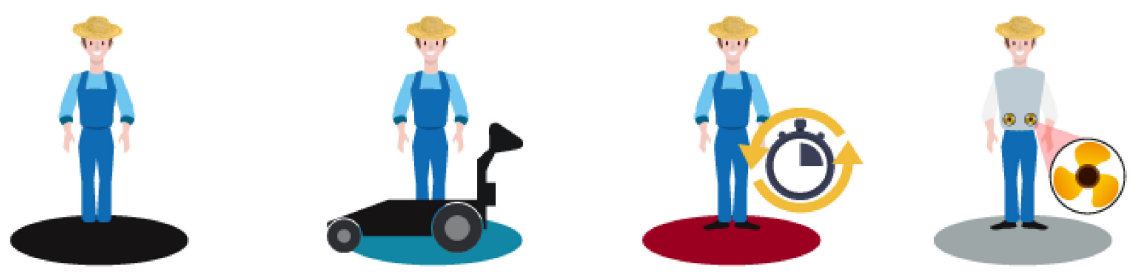

Figure 5. Differences (mean $\pm \mathrm{SD}$ ) in core temperature, mean skin temperature, heart rate, and metabolic rate/work intensity between "business as usual" and the tested heat mitigation strategies in the agriculture sector of Cyprus. Black, light blue, red, and grey colors represent "business as usual", mechanical fruit cart, planned breaks, and ventilated garments scenarios, respectively. Asterisk indicates statistically significant difference between "business as usual" and the tested heat mitigation strategy. Cohen's d effect sizes show the magnitude (small: 0.2 ; medium: 0.5 ; large: 0.8 ; very large: 1.2; huge: 2.0 ) and direction (positive: shades of red; negative: shades of blue) of the differences between "business as usual" and the tested heat mitigation strategies.

In Qatar, the hydration strategy increased workers' $\mathrm{HR}(p=0.009 ; \mathrm{d}=0.69)$ without affecting their $\mathrm{T}_{\text {core }}(p=0.457), \mathrm{T}_{\mathrm{sk}}(p=0.986)$, or labour effort $(p=0.779)$ (Figure 6). The hydration strategy also decreased the prevalence of dehydration by $54 \%$ ( $95 \%$ confidence interval: 1.06 to 2.24$)$. The evaporative garments strategy did not alter the $\mathrm{T}_{\text {core }}(p=0.512)$, $\mathrm{T}_{\mathrm{sk}}(p=0.606), \mathrm{HR}(p=0.262)$, or labor effort $(p=0.627)$ of agriculture workers, whereas providing them with "planned breaks" increased their HR $(p=0.006 ; \mathrm{d}=0.84)$ (Figure 6). 

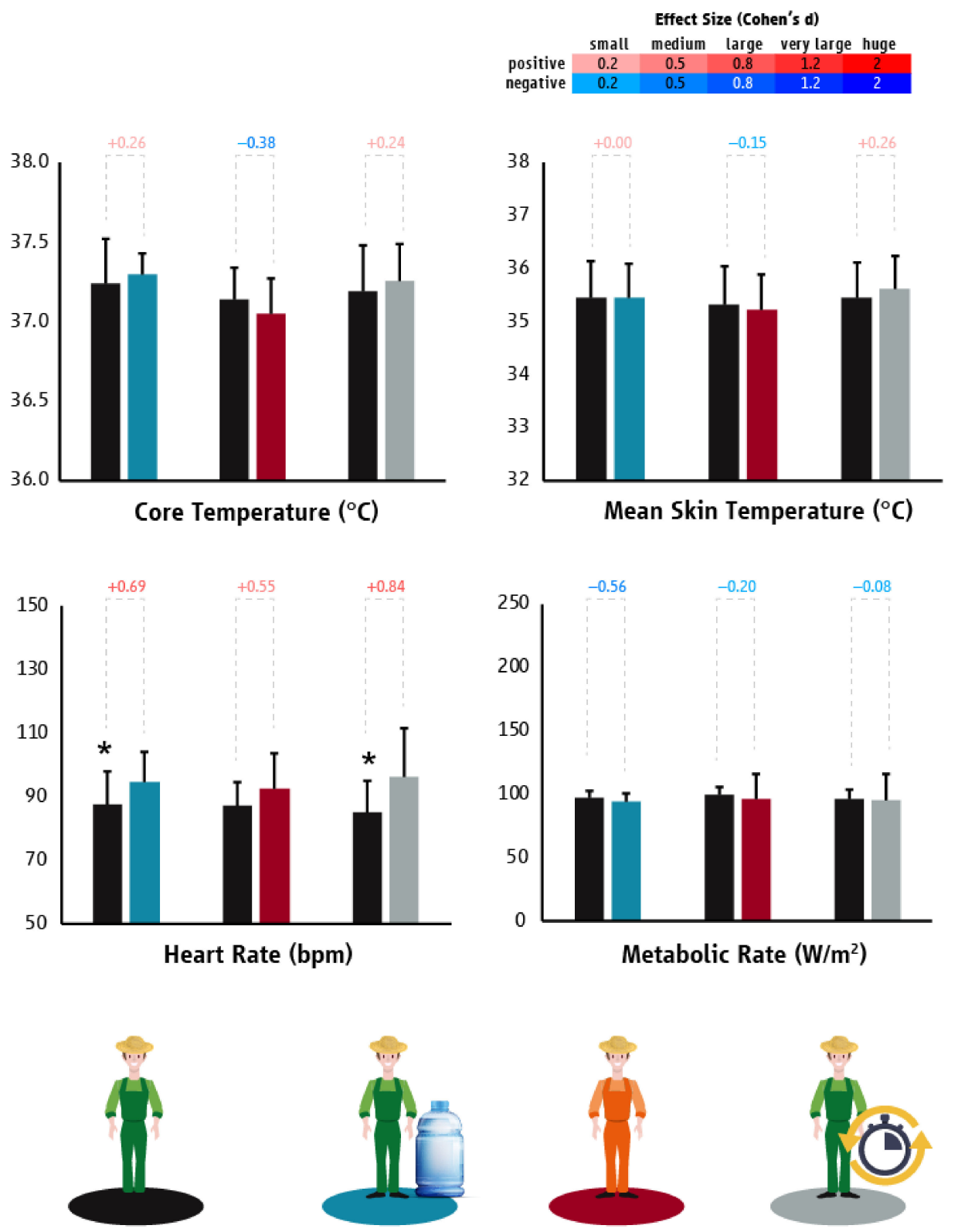

Figure 6. Differences (mean $\pm \mathrm{SD}$ ) in core temperature, mean skin temperature, heart rate, and metabolic rate/work intensity between "business as usual" and the tested heat mitigation strategies in the agriculture sector of Qatar. Black, light blue, red, and grey colors represent "business as usual", hydration, evaporative garments, and planned breaks scenarios, respectively. Asterisks indicate statistically significant differences between "business as usual" and the tested heat mitigation strategies. Cohen's d effect sizes show the magnitude (small: 0.2; medium: 0.5; large: 0.8; very large: 1.2; huge: 2.0) and direction (positive: shades of red; negative: shades of blue) of the differences between "business as usual" and the tested heat mitigation strategies.

\subsubsection{Construction Industry}

Heat mitigation strategies tested in Qatar showed that hydration reduced workers' $\mathrm{T}_{\text {core }}(p=0.035 ; \mathrm{d}=-0.45)$ without affecting their $\mathrm{T}_{\mathrm{sk}}(p=0.440), \operatorname{HR}(p=0.708)$, or labor effort $(p=0.944)$ (Figure 7). Moreover, the hydration strategy decreased the prevalence of dehydration by $97 \%$ (95\% confidence interval: 0.62 to 6.27 ). The evaporative garments strategy did not impact the $\mathrm{T}_{\text {core }}(p=0.250), \mathrm{T}_{\text {sk }}(p=0.440), \mathrm{HR}(p=0.164)$, or labor effort ( $p=0.077$ ) of the tested construction workers (Figure 7). A point of note here was that our research team observed that many workers did not follow the manufacturer's usage instructions for frequent wetting and often wore $t$-shirts underneath the evaporative 
garments. Providing construction workers with "planned breaks" significantly reduced their $\mathrm{T}_{\text {sk }}(p<0.001 ; \mathrm{d}=-0.64)$, HR $(p<0.001 ; \mathrm{d}=-0.28)$, and labor effort $(p<0.001$; $\mathrm{d}=-0.63)$ without affecting their $\mathrm{T}_{\text {core }}(p=0.901)$ (Figure 7).
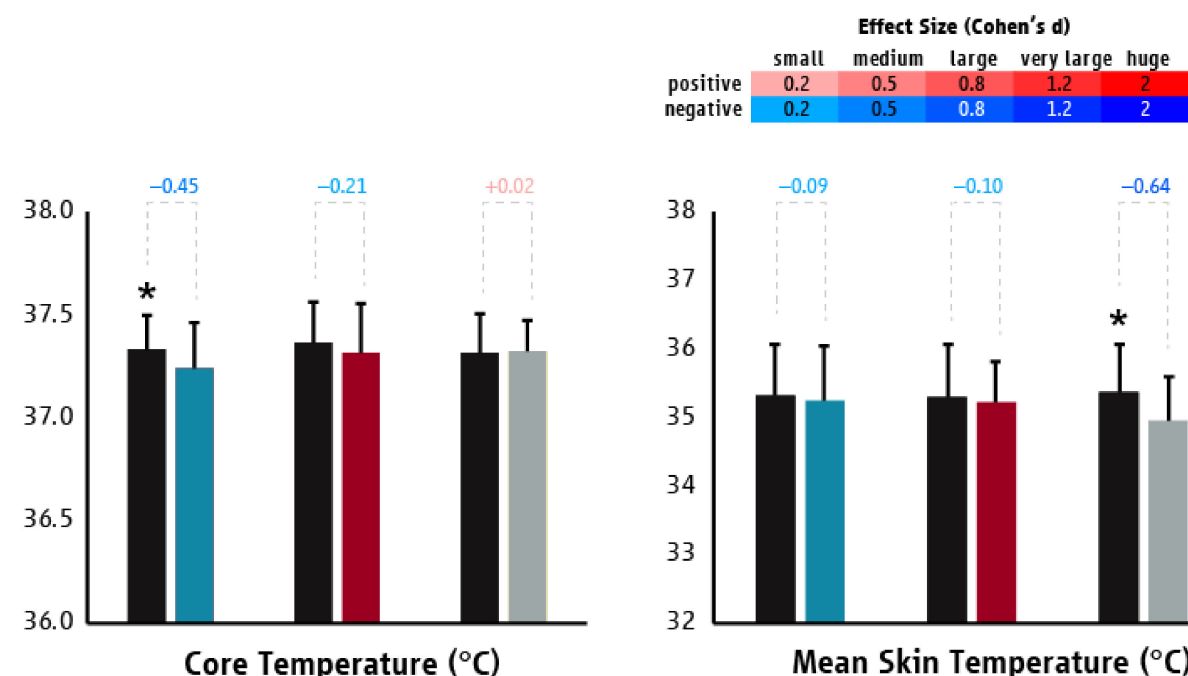

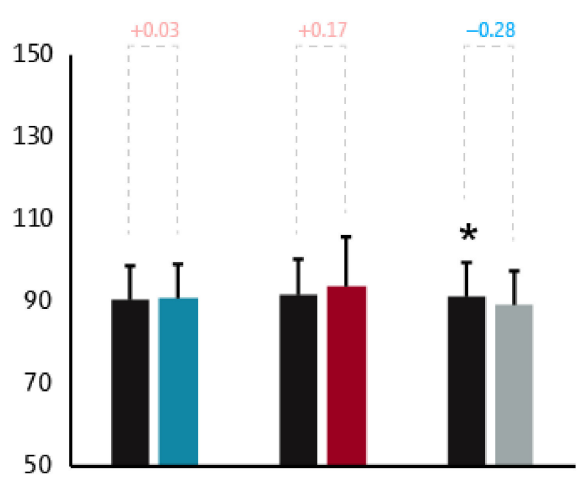

Heart Rate (bpm)
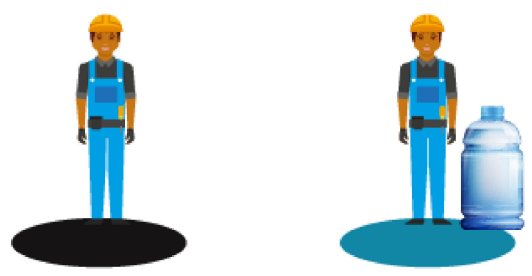

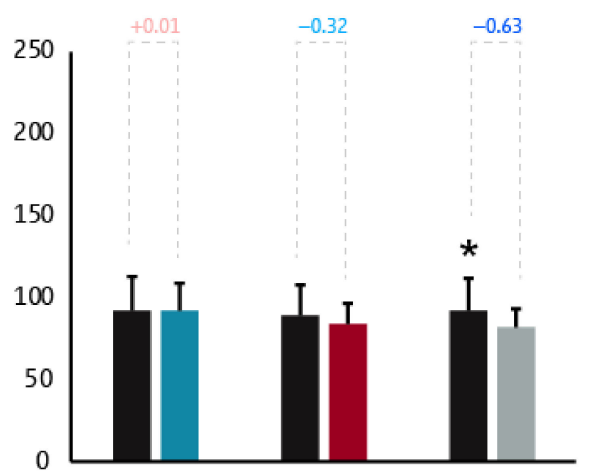

Metabolic Rate $\left(\mathrm{W} / \mathrm{m}^{2}\right)$
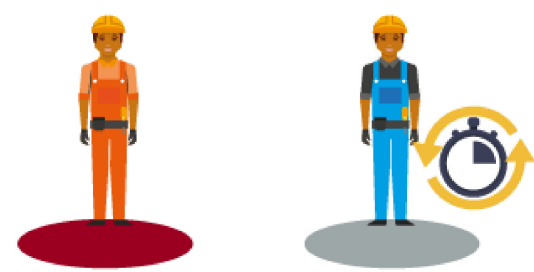

Figure 7. Differences (mean $\pm \mathrm{SD}$ ) in core temperature, mean skin temperature, heart rate, and metabolic rate/work intensity between "business as usual" and the tested heat mitigation strategies in the construction sector of Qatar. Black, light blue, red, and grey colors represent "business as usual", hydration, evaporative garments, and planned breaks scenarios, respectively. Asterisks indicate statistically significant differences between "business as usual" and the tested heat mitigation strategies. Cohen's d effect sizes show the magnitude (small: 0.2; medium: 0.5; large: 0.8 ; very large: 1.2; huge: 2.0) and direction (positive: shades of red; negative: shades of blue) of the differences between "business as usual" and the tested heat mitigation strategies.

In Spain, the tested hydration strategy reduced the $\mathrm{T}_{\text {core }}(p=0.022 ; \mathrm{d}=-1.07)$ and HR $(p=0.009 ; \mathrm{d}=-1.51)$ and increased the labor effort $(p=0.029 ; \mathrm{d}=0.39)$ of the tested construction workers (Figure 8 ). Moreover, hydration decreased the prevalence of dehydration by $13 \%$ ( $95 \%$ confidence interval: 0.78 to 1.63 ). Surprisingly, the $\mathrm{T}_{\mathrm{sk}}$ was increased during this heat mitigation strategy $(p=0.012 ; \mathrm{d}=1.28)$ compared to BAU 
(Figure 8). The "planned breaks" strategy did not impair workers' $\mathrm{T}_{\text {core }}(p=0.492), \mathrm{T}_{\text {sk }}$ $(p=0.893), \operatorname{HR}(p=0.079)$, or labor effort $(p=0.357)$ (Figure 7). The "ice slurry" strategy did not impair workers' $\mathrm{T}_{\text {core }}(p=0.649), \mathrm{HR}(p=0.157)$, or labor effort $(p=0.118)$, but increased $\mathrm{T}_{\mathrm{sk}}(p=0.034 ; \mathrm{d}=0.94)$ compared to BAU (Figure 8).
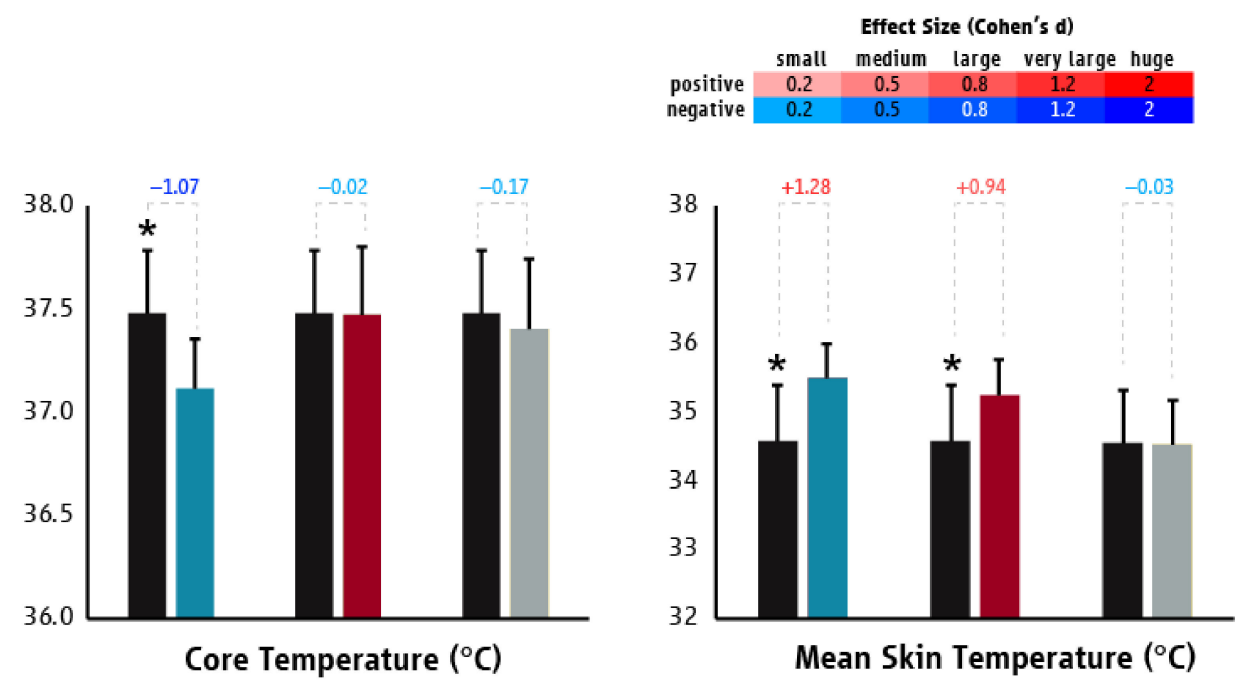

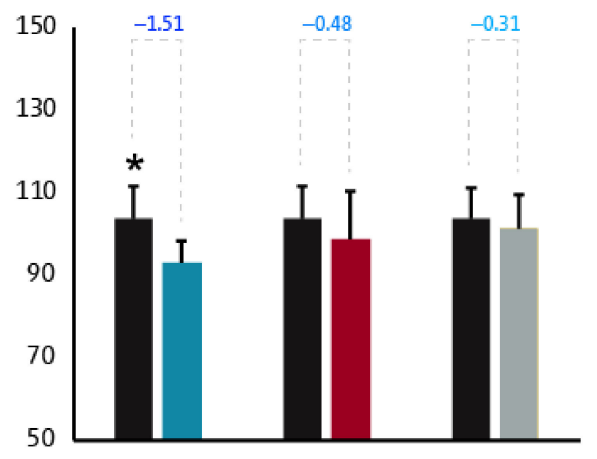

Heart Rate (bpm)
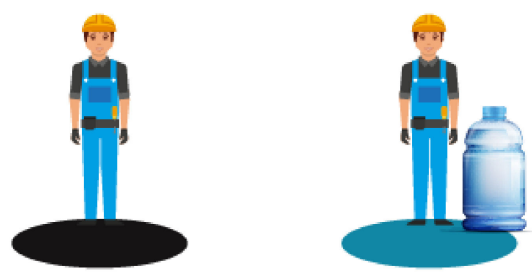

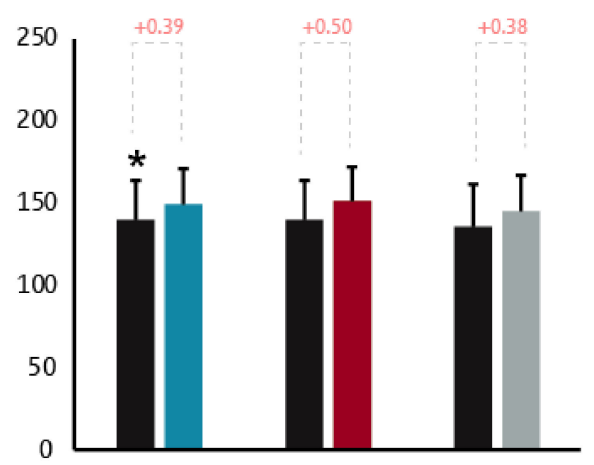

Metabolic Rate $\left(\mathrm{W} / \mathrm{m}^{2}\right)$
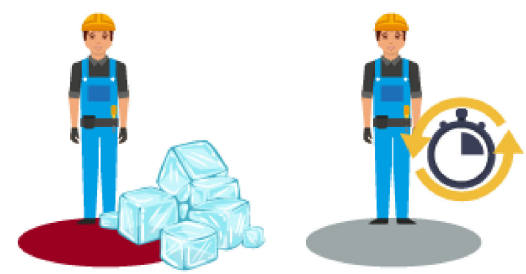

Figure 8. Differences (mean $\pm \mathrm{SD}$ ) in core temperature, mean skin temperature, heart rate, and metabolic rate/work intensity between "business as usual" and the tested heat mitigation strategies in the construction sector of Spain. Black, light blue, red, and grey colors represent "business as usual", hydration, ice slurry, and planned breaks scenarios, respectively. Asterisks indicate statistically significant differences between "business as usual" and the tested heat mitigation strategies. Cohen's $\mathrm{d}$ effect sizes show the magnitude (small: 0.2; medium: 0.5; large: 0.8 ; very large: 1.2 ; huge: 2.0 ) and direction (positive: shades of red; negative: shades of blue) of the differences between "business as usual" and the tested heat mitigation strategies.

\subsubsection{Tourism Industry}

The tested heat mitigation strategies in the Greek tourism industry did not impact workers' $\mathrm{T}_{\text {core }}$ (planned breaks: $p=0.430$; ice slurry: $p=0.094$; and combined: $p=0.135$ ), $\mathrm{T}_{\mathrm{sk}}$ (planned breaks: $p=0.909$; ice slurry: $p=0.628$; and combined: $p=0.326$ ), $\mathrm{HR}$ (planned 
breaks: $p=0.384$; ice slurry: $p=0.491$; and combined: $p=0.536$ ), or labor effort (planned breaks: $p=0.170$; ice slurry: $p=0.992$; and combined: $p=0.423$ ) (Figure 9). Despite the lack of statistically significant differences based on $p$ values, it is important to note that we found large effect sizes when comparing the $\mathrm{T}_{\text {core }}$ of workers between the BAU and either the "ice slurry" $(\mathrm{d}=0.83)$ or the "combined" $(\mathrm{d}=0.89)$ strategies, indicating that a larger sample size might have revealed a statistically significant difference.
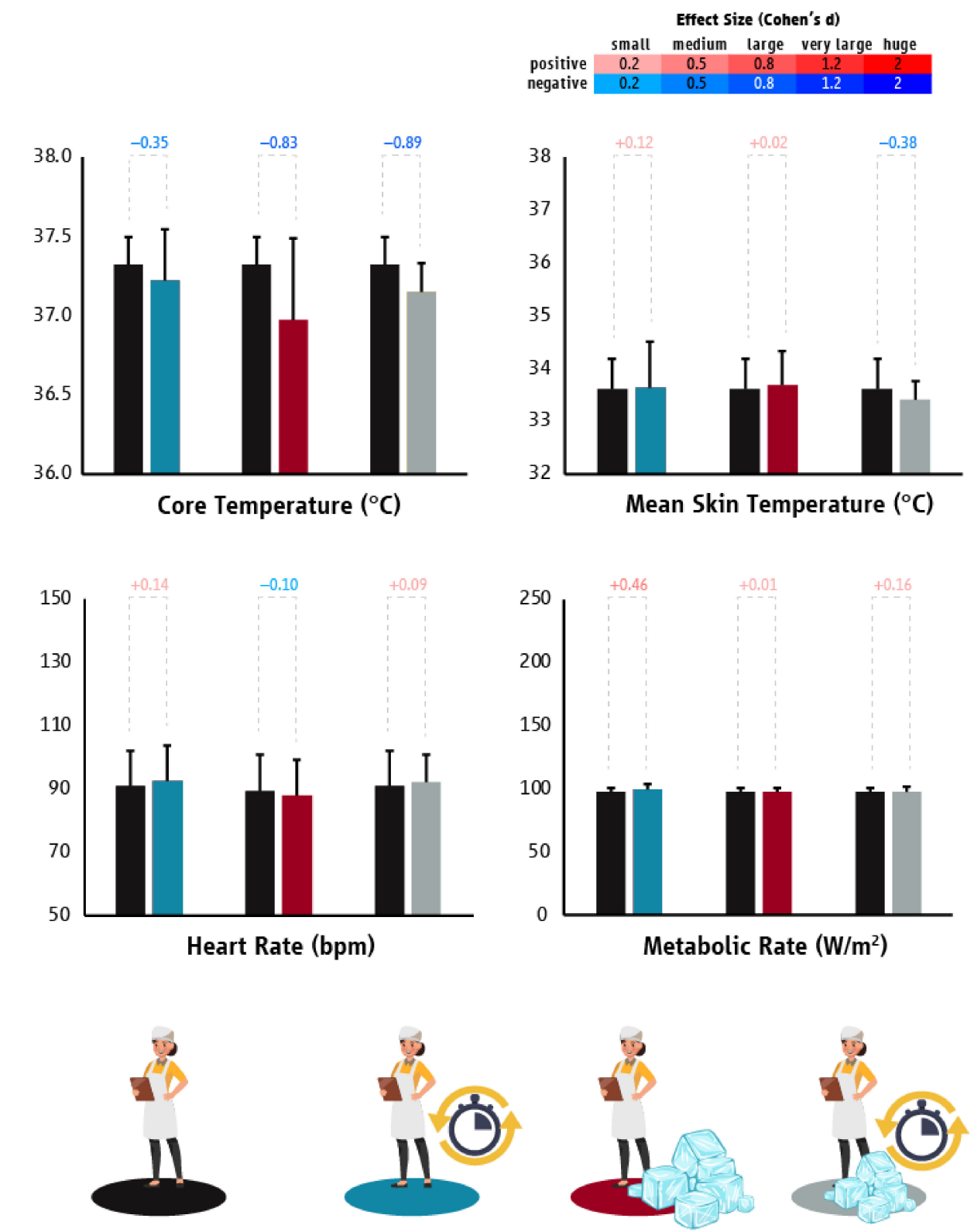

Figure 9. Differences (mean $\pm \mathrm{SD}$ ) in core temperature, mean skin temperature, heart rate, and metabolic rate/work intensity between "business as usual" and the tested heat mitigation strategies in the tourism sector of Greece. Black, light blue, red, and grey colors represent "business as usual", planned breaks, ice slurry, and "combined" (two minutes of planned break combined with ice slurry consumption (2.4 g per body mass kilogram) every hour of continuous work) scenarios, respectively. Cohen's d effect sizes show the magnitude (small: 0.2; medium: 0.5; large: 0.8; very large: 1.2; huge: 2.0) and direction (positive: shades of red; negative: shades of blue) of the differences between "business as usual" and the tested heat mitigation strategies. 


\section{Discussion}

The present paper with observational and intervention studies showed that $T_{\text {sk }}$ is positively associated with the $\mathrm{OH}$-stress experienced by workers in agriculture, construction, and tourism industries. On the other hand, we found that workers' $\mathrm{T}_{\text {core }}$ is associated with $\mathrm{OH}$-stress only when self-pacing is not feasible or is very limited. For instance, the monitored construction and tourism workers had limited capacity for self-pacing which predisposed them to $\mathrm{OH}$-strain. On the contrary, the studied agriculture workers maintain their $\mathrm{T}_{\text {core }}$ within a comfortable range by regulating their work intensity and consequently protecting themselves from experiencing increased $\mathrm{OH}$-strain. Although these findings of limited self-pacing in construction and tourism workers do not necessarily reflect the work practices in the entire construction and tourism sectors, our results are in line with previous studies confirming that self-pacing can maintain workers' $\mathrm{T}_{\text {core }}$ within a comfortable range despite being exposed to fluctuating harsh environmental conditions [38,39]. It is important to note that our findings of increased self-pacing in the agricultural sector may also reflect the higher metabolic demands characterizing the tasks performed by agriculture workers in comparison to people who work in the construction and tourism industries. Nevertheless, the observed increase in the $\mathrm{T}_{\text {core }}$ of workers who had limited ability for self-pacing highlights the proactive role of this important behavioral mechanism in the fight against $\mathrm{OH}$-strain [40].

Although self-pacing is undoubtedly an important aspect of behavioral thermoregulation acting as a catalyst to reduce the $\mathrm{OH}$-strain experienced by workers, it cannot guarantee adequate protection against $\mathrm{OH}$-stress when used alone. A previous laboratory study [41] showed that self-determined breaks are too short to allow complete thermal recovery, and therefore it seems unwise to rely completely on self-pacing to avoid $\mathrm{OH}$-strain even when workers are encouraged to adapt their own work pace [42]. It is more likely that the influence of exogenous environmental factors on the workers' health and physiological function requires the adoption of complementary heat mitigation strategies. Indeed, here we show that several heat mitigation strategies can be adopted to provide workers with protective mechanisms that are both inexpensive to use and flexible in time schedule.

Reducing the metabolic heat production in workplaces with high OH-stress is of great importance, and mechanization is considered a fundamental approach to achieve that goal [43]. To test this hypothesis, we provided agriculture workers with a mechanical fruit cart able to carry up to $225 \mathrm{~kg}$ of crops with minimal labor effort. Although we did not find significant differences in the $\mathrm{OH}$-strain experienced by agriculture workers when using the mechanical fruit cart compared to the BAU scenario, we showed that the use of the mechanical fruit cart led the workers to pick $63 \%$ more crops. Therefore, it is logical to assume that if a constant amount of crop was predefined, mechanization would be able to reduce the $\mathrm{OH}$-strain experienced by agriculture workers. This was confirmed using the predicted heat strain model $[30,44,45]$ which showed that the $T_{\text {core }}$ of these agriculture workers would be $0.3{ }^{\circ} \mathrm{C}$ lower after carrying $225 \mathrm{~kg}$ of crops with the mechanical fruit cart compared to the BAU scenario (both scenarios were simulated for the same workers performing manual labor in the same environmental conditions, but having a different metabolic rate).

Providing workers with planned breaks is another widely accepted method to reduce their metabolic heat production and protect them against OH-strain. Several studies $[46,47]$ previously examined the effects of the Threshold Limit Values [48] on the OH-strain experienced by workers. These work-rest cycles are based on WBGT and take into account acclimatization status and work intensity. However, although these work-rest cycles are adopted by many organizations including the US Occupational Safety and Health Administration [49], it has been shown that their applicability is limited in many occupational settings [46]. This, of course, is even more relevant in customer-depended industries and/or worksites where time can affect the quality of the final product or service. For this reason, we tested three different work-rest cycles tailored to our employers' needs and requirements. Our findings show that providing workers with $90 \mathrm{~s}$ of break every half hour 
of continuous work did not significantly affect the $\mathrm{OH}$-strain experienced by agriculture and tourism workers. Similarly, providing construction workers with two breaks of seven minutes throughout their work-shift did not alter their $\mathrm{OH}$-strain. On the other hand, providing construction workers with ten minutes of break every 50 min of continuous work was able to reduce their $\mathrm{T}_{\text {sk }}$ and HR, while it did not affect their $\mathrm{T}_{\text {core. Interestingly, }}$ the same heat mitigation strategy in agriculture showed a significant increase in the HR of workers, without affecting their $\mathrm{T}_{\mathrm{sk}}$ and $\mathrm{T}_{\text {core }}$. This is likely due to changes in the body posture of workers from crouching (i.e., typical posture during crop picking) to standing and walking during breaks. These findings are in line with previous studies showing that short work-rest cycles are not beneficial in mitigating the heat strain experienced by individuals during physical work in the heat [21,47,50,51].

Hydration status is of vital importance for workers' health and well-being, especially during work in the heat $[1,6]$. It is well established that hypohydration increases the heat stored in the body by limiting its ability to sweat and to send blood near the skin surface [52-54]. Our findings show that provision of $750 \mathrm{~mL}$ of water every hour can reduce the risk of dehydration by $54 \%$ among Qatar agriculture workers, by $97 \%$ among Qatar construction workers, and by $13 \%$ among Spanish construction workers. The hydration strategy also resulted in significantly reduced $\mathrm{T}_{\text {core, }}$ and it did not impact labor effort. These findings support the notion that hydration is the single most important and economically feasible mitigation strategy against $\mathrm{OH}$-strain.

Ice slurry consumption is another strategy previously used to mitigate the heat strain experienced by athletes $[55,56]$ and workers [24] who perform physical work in the heat. It is considered a highly effective strategy that takes advantage of the large $(334 \mathrm{~kJ} / \mathrm{kg})$ latent heat of fusion of water (quantity of energy required to change the phase of water from solid to liquid). Due to its limited practicality for remote work sites, we tested this strategy in construction and tourism. Our results showed a large effect size on $\mathrm{T}_{\text {core }}$ in Greek tourism workers, but no statistically significant differences on $\mathrm{T}_{\text {core }}$ in Greek tourism or Spanish construction workers. These findings are in line with a previous study [56] reporting no significant differences in the $\mathrm{T}_{\text {core }}$ and $\mathrm{T}_{\mathrm{sk}}$ of individuals who perform exercise in the heat between ice slurry ingestion and $37^{\circ} \mathrm{C}$ fluid ingestion. Therefore, it is reasonable to suggest that the benefits of ice slurry ingestion in our study were diluted by the cooling impact of other fluids that the workers consumed during the BAU scenario.

Clothing is ranked among the most important exogenous parameters affecting the efficiency of evaporative, convective, and radiative heat losses, leading to intense body heat gain in the heat [57]. Although this is a very well-known fact, there are technical aspects (e.g., need for protective clothing, helmet, boots, dress code, etc.) that may restrict the adoption of more efficient clothing strategies in occupational settings. Taking into account the aforementioned restrictions, we examined the capacity of two different garments to mitigate the $\mathrm{OH}$-strain experienced by workers in construction and agriculture industries. Our results indicate that providing agriculture workers with ventilated garments (shortsleeved shirts with integrated electric fans) reduced considerably their $\mathrm{T}_{\text {sk }}$ but did not affect their $\mathrm{T}_{\text {core }}, \mathrm{HR}$, or labor productivity during the work-shift. This finding is in line with previous studies showing that reducing physiological strain (i.e., $\mathrm{T}_{\mathrm{sk}}$ ) can be accomplished by the use of garments which provide greater ventilation and consequently enhanced evaporative and convective heat losses, even though $\mathrm{T}_{\text {core }}$ was not altered significantly [58]. On the other hand, providing workers with evaporative garments (breathable shirt and trousers allowing the wearer to wet parts of the garment) did not significantly affect workers' OH-strain or labor effort in construction or agriculture sectors. Observations made by our research team suggested that many workers did not follow the manufacturer's usage instructions for frequent wetting and often wore $t$-shirts underneath the evaporative garments.

It is important to note that the present study involved monitoring people working in developed countries, and thus our results may not reflect the practices and conditions under which workers perform their jobs in other parts of the world. Furthermore, although 
this series of field experiments involved a comparatively large sample size across different industries and countries, more focused interventions for gender-, age-, and body- specific differences should be conducted to elucidate the capacity of different interventions to mitigate the physiological heat strain experience by different working populations. Additionally, the rapid technological progress that is currently taking place is expected to enable new capabilities soon regarding the variety of physiological indicators that ecological studies can measure. For instance, wireless sweat rate and skin blood flow data loggers could soon be utilized to uncover even further aspects of occupational heat strain, triggering the development of more focused heat mitigation strategies. Furthermore, this technological progress may also enable the development of new techniques to examine labor productivity, minimizing possible differences between the time-motion analysis and real-time task analysis that were used in the present study. Another important limitation of our study is that the tested heat mitigation strategies were examined in various environmental conditions, and therefore we cannot directly compare the findings observed across different industries. For instance, agricultural tasks are characterized by prolonged exposure to intense solar radiation which may affect workers' capacity to perform their jobs, compared to people who work in the construction and tourism sectors. It is also important to note that, during the BAU scenario in the construction sectors of Qatar and Spain, a raft of other heat mitigation strategies was already in place, and this may not reflect the "business as usual" in other countries/workplaces. Furthermore, although our study involves testing different heat mitigation strategies across multiple countries characterized by high heat stress, we found that the monitored workers experienced low-to-moderate $\mathrm{OH}$-strain, and therefore this may undermine the capacity of a heat mitigation strategy to reduce the $\mathrm{OH}$-strain experienced by someone. Another important factor which may undermine the capacity of the tested heat mitigations strategies is self-pacing, indicating that in workplaces where self-pacing is limited, heat mitigation strategies may be of higher importance.

\section{Conclusions}

Taken together, our findings show that workers in the agriculture, construction, and tourism industries across Cyprus, Greece, Qatar, and Spain experience high levels of $\mathrm{OH}$-stress accompanied by low-to-moderate $\mathrm{OH}$-strain. However, when self-pacing is not feasible or very limited, the $\mathrm{OH}$-stress experienced by workers leads to higher levels of $\mathrm{OH}$-strain. Strategies targeting hydration, work-rest cycles, and ventilated garments show the most promising results towards mitigating OH-strain. Moreover, increasing mechanization - particularly for the most physically demanding tasks—can enhance labor productivity without increasing $\mathrm{OH}$-strain.

Author Contributions: Conceptualization, L.G.I., L.N. and A.D.F.; methodology, L.G.I., L.N. and A.D.F.; validation, L.G.I. and A.D.F.; formal analysis, L.G.I. and A.D.F.; investigation, L.G.I., K.M., L.T., E.N., M.V., P.G., C.N.D., G.G., G.A., K.S., A.K.K., D.J.T., T.A., P.C.D., T.S.M. and A.D.F.; resources, L.G.I., C.G., L.N. and A.D.F.; data curation, L.G.I., K.M., L.T., G.G. and A.D.F.; writing-original draft preparation, L.G.I. and A.D.F.; writing-review and editing, L.G.I., K.M., L.T., E.N., M.V., D.J.T., T.A., P.C.D., T.S.M., C.G., L.N. and A.D.F; visualization, L.G.I. and A.D.F.; supervision, A.D.F.; project administration, A.D.F.; funding acquisition, A.D.F. All authors have read and agreed to the published version of the manuscript.

Funding: The study has received funding from the International Labour Organization (Contract Number: 40262271/1) as well as from the European Union's Horizon 2020 research and innovation programme (project HEAT-SHIELD; Grant agreement No 668786).

Institutional Review Board Statement: The study was conducted according to the guidelines of the Declaration of Helsinki, and approved by the Bioethical Committee of School of Exercise Science of the University of Thessaly (no. 1217, 05 April 2017) and the National Bioethical Review Board of Cyprus (no. EEBK EP 2017.01.61, 11 May 2017).

Informed Consent Statement: Informed consent was obtained from all subjects involved in the study. 
Acknowledgments: We wish to thank the Qatar Ministry of Administrative Development, Labour and Social Affairs, as well as the Supreme Committee for Delivery and Legacy for their organizational support throughout the studies conducted in Qatar. Moreover, we wish to thank Acciona infrastructure company for the organizational support throughout the studies conducted in Spain.

Conflicts of Interest: The authors declare no conflict of interest.

\section{Appendix A}

Table A1. Determination of the intensity of each work task on the basis of time-motion analysis.

\begin{tabular}{|c|c|c|c|}
\hline Activity & $\begin{array}{l}\text { Metabolic } \\
\text { Equivalents }\end{array}$ & $\mathrm{W} / \mathrm{m}^{2}$ & $\begin{array}{c}\text { Compendium of Physical } \\
\text { Activities Code }\end{array}$ \\
\hline irregular work break taking place in the shade & 1.3 & 76 & 07021 \\
\hline planned lunch break & 1.5 & 87 & 13030 \\
\hline irregular work break taking place under the sun & 2.0 & 116 & 05160 \\
\hline giving instructions and guidance to the workers & 2.3 & 134 & 21015 \\
\hline moving the truck to a different place & 2.5 & 146 & 16050 \\
\hline helping other workers with their tasks & 3.5 & 204 & 11795 \\
\hline harvesting crops & 3.5 & 204 & 08246 \\
\hline driving and/or pushing the mechanical fruit cart & 4.5 & 262 & 21060 \\
\hline lifting boxes full of fruits & 4.5 & 262 & 20095 \\
\hline carrying empty fruit boxes (i.e., usually three to four boxes of $3 \mathrm{~kg}$ ) & 4.8 & 279 & 21065 \\
\hline carrying $25-\mathrm{kg}$-boxes full of fruits & 7.5 & 436 & reference [59] \\
\hline
\end{tabular}

Table A2. Results of all regression analyses. Dash signs indicate no statistically significant results. NL indicates that a non-linear regression (if WBGT $<30{ }^{\circ} \mathrm{C}$ then core temperature $=37.17043+\mathrm{WBGT} * 0.01007$; if WBGT $>30^{\circ} \mathrm{C}$ then core temperature $=37.17043+$ WBGT $* 0.39051$ ) was conducted to examine the impact of occupational heat stress on the core temperature of tourism workers.

\begin{tabular}{|c|c|c|c|c|c|c|c|c|c|c|c|c|}
\hline & \multicolumn{4}{|c|}{ Mean Skin Temperature $\left({ }^{\circ} \mathrm{C}\right)$} & \multicolumn{4}{|c|}{ Core Temperature $\left({ }^{\circ} \mathrm{C}\right)$} & \multicolumn{4}{|c|}{ Metabolic Rate $\left(\mathrm{W} / \mathrm{m}^{2}\right)$} \\
\hline & Inter. & Slope & $\mathrm{R}^{2}$ & $p$ & Inter. & Slope & $\mathrm{R}^{2}$ & $p$ & Inter. & Slope & $\mathrm{R}^{2}$ & $p$ \\
\hline Agriculture & 26.475 & 0.311 & 0.941 & $<0.001$ & - & - & - & - & 256.148 & -3.085 & 0.619 & $<0.001$ \\
\hline Construction & 27.145 & 0.225 & 0.850 & $<0.001$ & 36.400 & 0.047 & 0.585 & 0.010 & - & - & - & - \\
\hline Tourism & 31.381 & 0.090 & 0.354 & 0.032 & NL & NL & 0.852 & $<0.001$ & - & - & - & - \\
\hline
\end{tabular}

Table A3. Environmental conditions during heat mitigation strategies. Asterisks indicate significant difference between the "business as usual" (BAU) and the tested heat mitigation strategy (eCart, work rest ratio, ventilated garments, hydration, evaporative garments, ice slurry consumption, and a combination of ice slurry ingestion and breaks).

\begin{tabular}{|c|c|c|c|c|c|c|c|c|}
\hline \multicolumn{9}{|c|}{ Agriculture-Cyprus } \\
\hline & \multicolumn{2}{|c|}{ BAU } & \multicolumn{2}{|c|}{ eCart } & \multicolumn{2}{|c|}{ Work Rest Ratio } & \multicolumn{2}{|c|}{ Vent. Garments } \\
\hline & Mean & SD & Mean & SD & Mean & SD & Mean & SD \\
\hline $\mathrm{T}_{\text {air }}\left({ }^{\circ} \mathrm{C}\right)$ & 27.8 & 5.7 & 28.2 & 3.2 & 29.1 & 3.8 & 26.6 & 4.5 \\
\hline $\mathrm{T}_{\text {globe }}\left({ }^{\circ} \mathrm{C}\right)$ & 38 & 6.5 & 39.7 & 3.7 & 40.3 & 5.5 & 37.9 & 4.5 \\
\hline RH $(\%)$ & 35.0 & 13.3 & 54.4 & 12.3 & 49.5 & 10.9 & 38.5 & 11.5 \\
\hline $\mathrm{WS}(\mathrm{m} / \mathrm{s})$ & 0.9 & 1.1 & 1.3 & 1.0 & 1.0 & 0.9 & 1.0 & 1.1 \\
\hline WBGT $\left({ }^{\circ} \mathrm{C}\right)$ & 24.0 & 4.6 & $26.8 *$ & 2.9 & $27.0 *$ & 5.0 & 23.7 & 5.2 \\
\hline \multicolumn{9}{|c|}{ Agriculture-Qatar } \\
\hline & \multicolumn{2}{|c|}{ BAU } & \multicolumn{2}{|c|}{ Hydration } & \multicolumn{2}{|c|}{ Evap. garments } & \multicolumn{2}{|c|}{ Work rest ratio } \\
\hline & Mean & SD & Mean & $\mathrm{SD}$ & Mean & $\mathrm{SD}$ & Mean & $\mathrm{SD}$ \\
\hline $\mathrm{T}_{\text {air }}\left({ }^{\circ} \mathrm{C}\right)$ & 32.6 & 5.1 & 31.6 & 5.0 & 31.7 & 5.5 & 32.7 & 5.4 \\
\hline $\mathrm{T}_{\text {globe }}\left({ }^{\circ} \mathrm{C}\right)$ & 39.2 & 9.4 & 37.7 & 10.4 & 35.5 & 8.9 & 36.4 & 9.6 \\
\hline RH (\%) & 52.1 & 20.0 & 59.8 & 15.1 & 62.7 & 19.3 & 64.1 & 15.1 \\
\hline WS (m/s) & 3.5 & 1.9 & 0.6 & 0.6 & 0.9 & 0.8 & 0.6 & 0.6 \\
\hline WBGT $\left({ }^{\circ} \mathrm{C}\right)$ & 28.9 & 3.6 & 29.2 & 4.8 & 28.9 & 4.7 & 29.9 & 5.3 \\
\hline
\end{tabular}


Table A3. Cont.

\begin{tabular}{|c|c|c|c|c|c|c|c|c|}
\hline \multicolumn{9}{|c|}{ Construction-Qatar } \\
\hline & \multicolumn{2}{|c|}{ BAU } & \multicolumn{2}{|c|}{ Hydration } & \multicolumn{2}{|c|}{ Evap. garments } & \multicolumn{2}{|c|}{ Work rest ratio } \\
\hline & Mean & SD & Mean & SD & Mean & SD & Mean & SD \\
\hline $\mathrm{T}_{\text {air }}\left({ }^{\circ} \mathrm{C}\right)$ & 36.3 & 5.7 & 36.1 & 5.7 & 35.6 & 5.5 & 35.0 & 6.3 \\
\hline $\mathrm{T}_{\text {globe }}\left({ }^{\circ} \mathrm{C}\right)$ & 38.2 & 7.7 & 37.8 & 7.2 & 37.6 & 7.4 & 36.6 & 7.8 \\
\hline RH $(\%)$ & 30.4 & 12.1 & 33.2 & 14.2 & 37.8 & 15.0 & 39.3 & 23.2 \\
\hline WS (m/s) & 1.9 & 1.9 & 1.8 & 1.7 & 1.3 & 1.1 & 1.2 & 0.9 \\
\hline WBGT $\left({ }^{\circ} \mathrm{C}\right)$ & 27.6 & 3.6 & 27.8 & 3.5 & 28.2 & 3.9 & 27.5 & 4.2 \\
\hline \multicolumn{9}{|c|}{ Construction-Spain } \\
\hline & \multicolumn{2}{|c|}{ BAU } & \multicolumn{2}{|c|}{ Work rest } & \multicolumn{2}{|c|}{ Ice slurry } & \multicolumn{2}{|c|}{ Hydration } \\
\hline & Mean & SD & Mean & SD & Mean & SD & Mean & SD \\
\hline $\mathrm{T}_{\text {air }}\left({ }^{\circ} \mathrm{C}\right)$ & 30.5 & 1.2 & 30.7 & 2.1 & 30.5 & 1.8 & 30.7 & 1.4 \\
\hline $\mathrm{T}_{\text {globe }}\left({ }^{\circ} \mathrm{C}\right)$ & 38.9 & 3.5 & 37.3 & 4.0 & 36.8 & 2.7 & 36.2 & 1.9 \\
\hline RH (\%) & 55.1 & 5.7 & 55.2 & 7.3 & 53.5 & 8.3 & 32.9 & 3.8 \\
\hline $\mathrm{WS}(\mathrm{m} / \mathrm{s})$ & 1.8 & 0.8 & 0.8 & 0.7 & 0.7 & 0.6 & 1.0 & 0.8 \\
\hline WBGT $\left({ }^{\circ} \mathrm{C}\right)$ & 28.2 & 1.5 & 27.8 & 1.6 & 27.4 & 1.0 & $24.7^{*}$ & 0.8 \\
\hline \multicolumn{9}{|c|}{ Tourism-Greece } \\
\hline & \multicolumn{2}{|c|}{ BAU } & \multicolumn{2}{|c|}{ Work rest } & \multicolumn{2}{|c|}{ Ice slurry } & \multicolumn{2}{|c|}{ Combined } \\
\hline & Mean & SD & Mean & SD & Mean & SD & Mean & SD \\
\hline $\mathrm{T}_{\text {air }}\left({ }^{\circ} \mathrm{C}\right)$ & 28.5 & 1.6 & 28.2 & 1.6 & 28.5 & 0.7 & 27.3 & 1.2 \\
\hline $\mathrm{T}_{\text {globe }}\left({ }^{\circ} \mathrm{C}\right)$ & 28.4 & 1.6 & 28.1 & 1.7 & 28.4 & 0.7 & 27.2 & 1.2 \\
\hline RH (\%) & 45.2 & 5.4 & 46.5 & 5.3 & 44.5 & 3.1 & 46.5 & 3.6 \\
\hline WS (m/s) & 0.0 & 0.0 & 0.0 & 0.0 & 0.0 & 0.0 & 0.0 & 0.0 \\
\hline WBGT $\left({ }^{\circ} \mathrm{C}\right)$ & 22.9 & 0.9 & 23.0 & 1.0 & 22.9 & 0.7 & 22.1 & 0.8 \\
\hline
\end{tabular}

\section{References}

1. Piil, J.F.; Lundbye-Jensen, J.; Christiansen, L.; Ioannou, L.; Tsoutsoubi, L.; Dallas, C.N.; Mantzios, K.; Flouris, A.D.; Nybo, L. High prevalence of hypohydration in occupations with heat stress-Perspectives for performance in combined cognitive and motor tasks. PLoS ONE 2018, 13, e0205321. [CrossRef] [PubMed]

2. Tawatsupa, B.; Yiengprugsawan, V.; Kjellstrom, T.; Berecki-Gisolf, J.; Seubsman, S.-A.; Sleigh, A. Association between heat stress and occupational injury among Thai workers: Findings of the Thai Cohort Study. Ind. Health 2013, 51, 34-46. [CrossRef] [PubMed]

3. Page, L.; Sheppard, S. Heat Stress: The Impact of Ambient Temperature on Occupational Injuries in the US; Department of Economics Working Papers: Williamstown, MA, USA, 2016.

4. Varghese, B.M.; Hansen, A.; Bi, P.; Pisaniello, D. Are workers at risk of occupational injuries due to heat exposure? A comprehensive literature review. Saf. Sci. 2018, 110, 380-392. [CrossRef]

5. Zander, K.K.; Botzen, W.J.; Oppermann, E.; Kjellstrom, T.; Garnett, S.T. Heat stress causes substantial labour productivity loss in Australia. Nat. Clim. Chang. 2015, 5, 647. [CrossRef]

6. Flouris, A.D.; Dinas, P.C.; Ioannou, L.G.; Nybo, L.; Havenith, G.; Kenny, G.P.; Kjellstrom, T. Workers' health and productivity under occupational heat strain: A systematic review and meta-analysis. Lancet Planet Health 2018, 2, e521-e531. [CrossRef]

7. Ioannou, L.G.; Tsoutsoubi, L.; Samoutis, G.; Bogataj, L.K.; Kenny, G.P.; Nybo, L.; Kjellstrom, T.; Flouris, A.D. Time-motion analysis as a novel approach for evaluating the impact of environmental heat exposure on labor loss in agriculture workers. Temperature 2017, 4, 1-11. [CrossRef]

8. Ioannou, L.G.; Mantzios, K.; Tsoutsoubi, L.; Panagiotaki, Z.; Kapnia, A.K.; Ciuha, U.; Nybo, L.; Flouris, A.D.; Mekjavic, I.B. Effect of a simulated heat wave on physiological strain and labour productivity. Int. J. Environ. Res. Public Health 2021, $18,3011$. [CrossRef]

9. Mora, C.; Dousset, B.; Caldwell, I.R.; Powell, F.E.; Geronimo, R.C.; Bielecki, C.R.; Counsell, C.W.; Dietrich, B.S.; Johnston, E.T.; Louis, L.V. Global risk of deadly heat. Nat. Clim. Chang. 2017, 7, 501. [CrossRef]

10. International Labour Organization. Working on a Warmer Planet: The Impact of Heat Stress on Labour Productivity and Decent Work; International Labour Organization: Geneva, Switzerland, 2019.

11. Amelung, B.; Nicholls, S.; Viner, D. Implications of global climate change for tourism flows and seasonality. J. Travel Res. 2007, 45, 285-296. [CrossRef]

12. Wästerlund, S. Managing Heat in Agricultural Work: Increasing Worker Safety and Productivity by Controlling Heat Exposure; FAO: Roma, Italy, 2018; Volume 53. 
13. Buckley, M.; Zendel, A.; Biggar, J.; Frederiksen, L.; Wells, J. Migrant Work E Employment in the Construction Sector; International Labour Office: Geneva, Switzerland, 2016.

14. International Labour Organization. Global Dialogue Forum on New Developments and Challenges in the Hospitality and Tourism Sector and their impact on Employment, Human Resources Development and Industrial Relations; International Labour Organization: Geneva, Switzerland, 2010.

15. DARA: Climate Vulnerable Forum. Climate Vulnerability Monitor: A Guide to the Cold Calculus of a Hot Planet, 2nd ed.; DARA: Madrid, Spain, 2012.

16. Morris, N.B.; Levi, M.; Morabito, M.; Messeri, A.; Ioannou, L.G.; Flouris, A.D.; Samoutis, G.; Pogačar, T.; Bogataj, L.K.; Piil, J.F.; et al. Health vs. wealth: Employer, employee and policy-maker perspectives on occupational heat stress across multiple European industries. Temperature 2020, 1-18. [CrossRef]

17. Morris, N.B.; Piil, J.F.; Morabito, M.; Messeri, A.; Levi, M.; Ioannou, L.G.; Ciuha, U.; Pogačar, T.; Kajfež Bogataj, L.; Kingma, B.; et al. The HEAT-SHIELD project-Perspectives from an inter-sectoral approach to occupational heat stress. J. Sci. Med. Sport 2021. [CrossRef]

18. Flouris, A.D.; Ioannou, L.G.; Dinas, P.C.; Mantzios, K.; Gkiata, P.; Gkikas, G.; Vliora, M.; Amorim, T.; Tsoutsoubi, L.; Kapnia, A.; et al. Assessment of Occupational Heat Strain and Mitigation Strategies in Qatar; International Labour Organization: Doha, Qatar, 2019.

19. Bodin, T.; García-Trabanino, R.; Weiss, I.; Jarquín, E.; Glaser, J.; Jakobsson, K.; Lucas, R.; Wesseling, C.; Hogstedt, C.; Wegman, D. Intervention to reduce heat stress and improve efficiency among sugarcane workers in El Salvador: Phase 1. Occup. Environ. Med. 2016, 73, 409-416. [CrossRef]

20. Morris, N.B.; Jay, O.; Flouris, A.D.; Casanueva, A.; Gao, C.; Foster, J.; Havenith, G.; Nybo, L. Sustainable solutions to mitigate occupational heat strain-An umbrella review of physiological effects and global health perspectives. Environ. Health 2020, 19, 95. [CrossRef]

21. Meade, R.D.; Poirier, M.P.; Flouris, A.D.; Hardcastle, S.G.; Kenny, G.P. Do the threshold limit values for work in hot conditions adequately protect workers? Med. Sci. Sports Exerc. 2016, 48, 1187-1196. [CrossRef]

22. Bach, A.J.E.; Maley, M.J.; Minett, G.M.; Zietek, S.A.; Stewart, K.L.; Stewart, I.B. An evaluation of personal cooling systems for reducing thermal strain whilst working in chemical/biological protective clothing. Front. Physiol. 2019, 10, 424. [CrossRef]

23. Gao, C.; Kuklane, K.; Holmér, I. Cooling vests with phase change materials: The effects of melting temperature on heat strain alleviation in an extremely hot environment. Eur. J. Appl. Physiol. 2011, 111, 1207-1216. [CrossRef]

24. Maté, J.; Siegel, R.; Oosthuizen, J.; Laursen, P.; Watson, G. Effect of liquid versus ice slurry ingestion on core temperature during simulated mining conditions. Sci. Res. 2016. [CrossRef]

25. Yi, W.; Chan, A.P.C.; Wong, F.K.W.; Wong, D.P. Effectiveness of a newly designed construction uniform for heat strain attenuation in a hot and humid environment. Appl. Ergon. 2017, 58, 555-565. [CrossRef]

26. Barwood, M.J.; Newton, P.S.; Tipton, M.J. Ventilated vest and tolerance for intermittent exercise in hot, dry conditions with military clothing. Aviat. Space Environ. Med. 2009, 80, 353-359. [CrossRef]

27. Zhao, M.; Gao, C.; Wang, F.; Kuklane, K.; Holmér, I.; Li, J. A study on local cooling of garments with ventilation fans and openings placed at different torso sites. Int. J. Ind. Ergon. 2013, 43, 232-237. [CrossRef]

28. Piil, J.F.; Christiansen, L.; Morris, N.B.; Mikkelsen, C.J.; Ioannou, L.G.; Flouris, A.D.; Lundbye-Jensen, J.; Nybo, L. Direct exposure of the head to solar heat radiation impairs motor-cognitive performance. Sci. Rep. 2020, 10, 7812. [CrossRef]

29. Ramanathan, N.L. A new weighting system for mean surface temperature of the human body. J. Appl. Physiol. 1964, 19, 531-533. [CrossRef]

30. Ioannou, L.G.; Tsoutsoubi, L.; Mantzios, K.; Flouris, A.D. A free software to predict heat strain according to the ISO $7933: 2018$. Ind. Health 2019, 57, 711-720. [CrossRef]

31. Ainsworth, B.E.; Haskell, W.L.; Herrmann, S.D.; Meckes, N.; Bassett, D.R., Jr.; Tudor-Locke, C.; Greer, J.L.; Vezina, J.; Whitt-Glover, M.C.; Leon, A.S. 2011 compendium of physical activities: A second update of codes and MET values. Med. Sci. Sports Exerc. 2011, 43, 1575-1581. [CrossRef]

32. Poulianiti, K.P.; Havenith, G.; Flouris, A.D. Metabolic energy cost of workers in agriculture, construction, manufacturing, tourism, and transportation industries. Ind. Health 2018. [CrossRef]

33. Sawka, M.N.; Burke, L.M.; Eichner, E.R.; Maughan, R.J.; Montain, S.J.; Stachenfeld, N.S. American College of Sports Medicine position stand. Exercise and fluid replacement. Med. Sci. Sports Exerc. 2007, 39, 377-390.

34. Ngoan, L.T.; Yoshimura, T. Work, salt intake and the development of stomach cancer. Med. Hypotheses 2003, 60, 552-556. [CrossRef]

35. Schober, P.; Boer, C.; Schwarte, L.A. Correlation coefficients: Appropriate use and interpretation. Anesth. Analg. 2018, 126, 1763-1768. [CrossRef]

36. Sawilowsky, S.S. New effect size rules of thumb. J. Mod. Appl. Stat. Methods 2009, 8, 26. [CrossRef]

37. Altman, D.G. Practical Statistics for Medical Research; CRC Press: Boca Raton, FL, USA, 1990.

38. Bates, G.P.; Schneider, J. Hydration status and physiological workload of UAE construction workers: A prospective longitudinal observational study. J. Occup. Med. Toxicol. 2008, 3, 21. [CrossRef]

39. Miller, V.; Bates, G.; Schneider, J.D.; Thomsen, J. Self-pacing as a protective mechanism against the effects of heat stress. Ann. Occup. Hyg. 2011, 55, 548-555. [CrossRef] [PubMed] 
40. Flouris, A.D.; Schlader, Z.J. Human behavioral thermoregulation during exercise in the heat. Scand. J. Med. Sci. Sports 2015, 25, 52-64. [CrossRef] [PubMed]

41. Vogt, J.; Libert, J.; Candas, V.; Daull, F.; Mairjaux, P. Heart rate and spontaneous work-rest cycles during exposure to heat. Ergonomics 1983, 26, 1173-1185. [CrossRef] [PubMed]

42. Wästerlund, D.S. A review of heat stress research with application to forestry. Appl. Ergon. 1998, 29, 179-183. [CrossRef]

43. Choi, J.-W.; Kim, M.-J.; Lee, J.-Y. Alleviation of heat strain by cooling different body areas during red pepper harvest work at WBGT $33^{\circ} \mathrm{C}$. Ind. Health 2008, 46, 620-628. [CrossRef]

44. ISO. ISO 7933, Ergonomics of the Thermal Environment-Analytical Determination and Interpretation of Heat Stress Using Calculation of the Predicted Heat Strain; ISO: Geneva, Switzerland, 2004.

45. ISO. ISO/DIS 7933, Ergonomics of the Thermal Environment-Analytical Determination and Interpretation of Heat Stress Using the Predicted Heat Strain Model; ISO: Geneva, Switzerland, 2018.

46. Dehghan, H.; Mortazavi, S.; Jafari, M.; Maracy, M.; Jahangiri, M. The evaluation of heat stress through monitoring environmental factors and physiological responses in melting and casting industries workers. Int. J. Environ. Health Eng. $2012,1,21$.

47. Lamarche, D.T.; Meade, R.D.; D'Souza, A.W.; Flouris, A.D.; Hardcastle, S.G.; Sigal, R.J.; Boulay, P.; Kenny, G.P. The recommended Threshold Limit Values for heat exposure fail to maintain body core temperature within safe limits in older working adults. J. Occup. Environ. Hyg. 2017, 14, 703-711. [CrossRef]

48. American Conference of Governmental Industrial Hygienists (ACGIH). TLVs and BEIs, Threshold Limit Values for Chemical Substances and Physical Agents and Biological Exposure Indices; Signature Publications: Cincinnati, OH, USA, 2012.

49. OSHA. OSHA Technical Manual. Available online: https://www.osha.gov/dts/osta/otm/otm_iii/otm_iii_4.html (accessed on 9 June 2021).

50. Horn, G.P.; Gutzmer, S.; Fahs, C.A.; Petruzzello, S.J.; Goldstein, E.; Fahey, G.C.; Fernhall, B.; Smith, D.L. Physiological recovery from firefighting activities in rehabilitation and beyond. Prehospital Emerg. Care 2011, 15, 214-225. [CrossRef]

51. Pryor, R.R.; Hostler, D.; Cooper, E.R.; Grundstein, A.J. Work-to-Rest Ratio. In Sport and Physical Activity in the Heat; Springer: Amsterdam, The Netherlands, 2018; pp. 101-111.

52. Sawka, M.N.; Montain, S.J.; Latzka, W.A. Hydration effects on thermoregulation and performance in the heat. Comp. Biochem. Physiol. Part. A Mol. Integr. Physiol. 2001, 128, 679-690. [CrossRef]

53. Sawka, M.; Latzka, W.; Matott, R.; Montain, S. Hydration effects on temperature regulation. Int. J. Sports Med. 1998, 19, S108-S110. [CrossRef]

54. Flouris, A.D. Human Thermoregulation. In Heat Stress in Sport and Exercise; Springer: Amsterdam, The Netherlands, 2019; pp. 3-27.

55. Stevens, C.J.; Dascombe, B.; Boyko, A.; Sculley, D.; Callister, R. Ice slurry ingestion during cycling improves Olympic distance triathlon performance in the heat. J. Sports Sci. 2013, 31, 1271-1279. [CrossRef]

56. Morris, N.B.; Coombs, G.; Jay, O. Ice slurry ingestion leads to a lower net heat loss during exercise in the heat. Med. Sci. Sports Exerc. 2016, 48, 114-122. [CrossRef]

57. Notley, S.R.; Flouris, A.D.; Kenny, G.P. On the use of wearable physiological monitors to assess heat strain during occupational heat stress. Appl. Physiol. Nutr. Metab. 2018, 43, 869-881. [CrossRef]

58. Yazdi, M.M.; Sheikhzadeh, M. Personal cooling garments: A review. J. Text. Inst. 2014, 105, 1231-1250. [CrossRef]

59. Tudor-Locke, C.; Ainsworth, B.E.; Washington, T.L.; Troiano, R. Assigning metabolic equivalent values to the 2002 census occupational classification system. J. Phys. Act. Health 2011, 8, 581-586. [CrossRef] 